\title{
Climate-driven sea level extremes compounded by marine heatwaves in coastal Indonesia
}

\section{Weiqing Han ( $\nabla$ whan@colorado.edu )}

University of Colorado

\section{Lei Zhang}

Department of Atmospheric and Oceanic Sciences, University of Colorado

\section{Gerald Meehl}

National Center for Atmospheric Research https://orcid.org/0000-0002-8760-9534

\section{Shoichiro Kido}

Jamstec

\section{Tomoki Tozuka}

The University of Tokyo

\section{Yuanlong Li}

The University of Colorado

\section{Michael McPhaden}

NOAA/PMEL https://orcid.org/0000-0002-8423-5805

\section{Aixue $\mathrm{Hu}$}

National Center for Atmospheric Research https://orcid.org/0000-0002-1337-287X

\section{Anny Cazenave}

LEGOS-CNES

\section{Nan Rosenbloom}

NCAR https://orcid.org/0000-0001-7389-3346

\section{Gary Strand}

NCAR

\section{Bryan West}

GSFC, NASA

\section{Article}

Keywords: climate change, sea level extremes, marine heatwaves, Indonesia

Posted Date: April 19th, 2021

DOI: https://doi.org/10.21203/rs.3.rs-310860/v1 
License: (c) (i) This work is licensed under a Creative Commons Attribution 4.0 International License. Read Full License 
1 Climate-driven sea level extremes compounded by marine heatwaves in coastal Indonesia

2 Weiqing Han $^{1 *}$, Lei Zhang ${ }^{1}$, Gerald A. Meehl², Shoichiro Kido ${ }^{3}$, Tomoki Tozuka ${ }^{3,4}$, Yuanlong

$3 \mathrm{Li}^{1,5}$, Michael J. McPhaden ${ }^{6}$, Aixue $\mathrm{Hu}^{2}$, Anny Cazenave ${ }^{7}$, Nan Rosenbloom ${ }^{2}$, Gary Strand ${ }^{2}$, and

4 B. Jason West ${ }^{8}$

$5{ }^{1}$ Department of Atmospheric and Oceanic Sciences, University of Colorado, UCB 311, Boulder,

6 Colorado 80309,USA; whan@colorado.edu; Tel: 303-735-3079

$7 \quad{ }^{2}$ Climate and Global Dynamics Laboratory, the National Center for Atmospheric Research,

8 Boulder, Colorado 80305, USA

$9 \quad{ }^{3}$ Application Laboratory, Research Institute for Value - Added - Information Generation, Japan

10 Agency for Marine - Earth Science and Technology, Kanagawa, Japan

$11{ }^{4}$ Graduate School of Science, University of Tokyo, Tokyo, Japan

$12{ }^{5}$ CAS Key Laboratory of Ocean Circulation and Waves, Institute of Oceanology and Center for Ocean

13 Mega-Science, Chinese Academy of Sciences, Chinese Academy of Sciences, Qingdao, China

$14{ }^{6}$ Pacific Marine Environmental Laboratory, National Oceanic and Atmospheric Administration,

15 Seattle, WA, USA

$16 \quad{ }^{7}$ Laboratoire d'Etudes en Géophysique et Océanographie Spatiales (LEGOS)

1718 Av. E. Belin, 31401 Toulouse cedex 9, France; and International Space Science Institute (ISSI)

18

Hallerstrasse 6, CH-3012 Bern, Switzerland

$19{ }^{8}$ NASA, Precipitation Processing System and KBR, Inc., Goddard Space Flight Center,

20 Greenbelt, MD, USA 
21 The low-lying coastal and island regions are vulnerable to sea level rise and extreme events.

22 Compounded by marine heatwaves, sea level extremes have devastating impacts on coastal community and marine ecosystems. As long tide gauge records are sparse, sea level extremes around Indonesia are poorly understood, and the Compound Height-Heat EXtreme (C-HHEX) events remain unexplored. Here we combine in situ and satellite observations with model simulations, to investigate the long-lasting ( $>1$ month) sea level extremes and C-HHEXs along Indonesian coasts of the Indian Ocean since the 1960s. We find that $90 \%(80 \%)$ of the extreme sea level (C-HHEX) events, with a maximum monthly sea level anomaly of $0.45 \mathrm{~m}$, are clustered in an $8 y$ r period of $2010-2017$, due to anthropogenic global sea level rise and decadal enhancement driven by changing surface winds associated with a combined invigoration of the Indian and Pacific Walker Cells, atmospheric overturning circulations in east-west direction. Remote and local surface wind anomalies associated with negative phases of the Indian Ocean Dipole (IOD) - enhanced by La Niña - drive individual C-HHEX events under a precondition of shallow thermocline (a region of subsurface ocean with temperature decreases rapidly downward). By contrast, winds associated with monsoon and its intraseasonal oscillations force the sea level alone events under a deep thermocline condition. We conclude that the shoaling thermocline in eastern Indian Ocean under anthropogenic warming and global sea level rise favorably precondition the ocean for stronger and more frequent sea level extremes and C-HHEXs, increasing the environmental stress on Indonesia.

Extreme sea level events are one of the most consequential impacts of climate change ${ }^{1-3}$. Global sea level rise over the past century has magnified flooding and caused clear-sky floods in many coastal regions around the world ${ }^{4}$. While much emphasis has been placed on extreme sea levels 
44 induced by storms and high tides on daily time scales $^{5}$, the interplay of longer-lasting sea level extremes driven by intraseasonal-to-interannual climate variability with decadal variability and

46 anthropogenic warming has received less attention. As the dominant mode of interannual climate

47 variability across tropical oceans, the El Niño and Southern Oscillation $\left(\mathrm{ENSO}^{6}\right)$ induces long-

48 lasting sea level extremes ${ }^{7-10}$ and increases the frequency of storm surges ${ }^{11}$ along the west coasts

49 of the South and North Americas during its positive phase (i.e., El Niño). El Niño also generates

50 intense and more frequent marine heatwaves in the eastern Pacific Ocean ${ }^{12-14}$, causing disastrous

51 impacts in many coastal areas of the Americas. While individual sea level extremes and marine

52 heatwaves in isolation can have large ecological, economic, and social consequences ${ }^{15,16}$, in

53 combination they can be much more devastating ${ }^{17,12}$ and the compound extremes in earth's

54 climate system (e.g., heatwave and drought) are becoming more common in a warming climate ${ }^{18}$.

55 Yet, integrated studies of sea level extremes and marine heatwaves - dubbed Compound Height-

56 Heat EXtreme (C-HHEX) events - are still in its infancy. A better understanding of extremes and

57 their compounds will improve risk assessments, decadal prediction and future projections of

58 high-impact events ${ }^{17,19}$.

59 The Indian Ocean rim region hosts one-third of the world's population mostly from

60 developing countries with low-lying coastal areas that are highly vulnerable to climate

61 variability and change. Located at the confluence of the tropical eastern Indian Ocean and

62 western Pacific and being home for diversified coral reefs, Indonesia experiences rapid

63 urbanization on Java island and population growth in low-lying areas, which further increase its

64 vulnerability to climate change ${ }^{1,3}$. Detecting and understanding sea level extremes and C-HHEX

65 along Indonesian coast in a changing climate will help predict these events, and therefore 
66 achieve informed decision making. Although each ocean may have some unique aspect, results

67 from this study may be translated to other regions of the world's oceans.

68 Here, for the first time, we use in situ and satellite observations to detect climate-driven extreme

69 sea level and C-HHEX events that last for one to a few months around Indonesian coasts of the

70 Indian Ocean since 1993. This time period represents the satellite altimetry era when accelerated

71 global sea level rise has been detected and attributed largely to human-induced climate change ${ }^{20-}$

$72 \quad 22$. To assess the extremes in a longer-term context, we extend our analysis to the 1960s using

73 reanalysis products that are model hindcasts assimilated observational data. To understand the

74 causes for these extremes, we carry out model experiments using two independent ocean general

75 circulation models - the Regional Ocean Modelling System $\left(\mathrm{ROMS}^{23}\right)$ and the Hybrid

76 Coordinate Ocean Model $\left(\mathrm{HYCOM}^{24}\right)$ - and a global Earth system model, the Community Earth

77 System Model version $1\left(\mathrm{CESM}^{25}\right)$ of the National Center for Atmospheric Research. To

78 quantify the effects of remote versus local wind forcing, we employ a Bayesian dynamical linear

79 model $^{26}$. To assess the impacts of external forcing (natural plus anthropogenic) on regional sea

80 level, we analyze the results from large ensemble experiments of Coupled Model

81 Intercomparison Project phase 6 (CMIP6) assessed in the Intergovernmental Panel on Climate

82 Change Sixth Assessment Report (IPCC AR6). See Methods section for details.

83 Detection of the extreme events Satellite altimeter data from 1993-2018 ${ }^{27}$ show rapid sea level

84 rise along the east coasts of tropical Indian Ocean, with a rising rate of $5.12 \pm 0.17 \mathrm{~mm} / \mathrm{yr}$ near

85 the tide gauge station at Java coast (Fig 1a) compared to the $3.1 \pm 0.3 \mathrm{~mm} / \mathrm{yr}$ global mean

86 rise ${ }^{20,21,28}$. Accompanied with the rapid sea level rise is weak sea surface warming at the Java

87 coast and stronger warming along southern coast of Sumatra (Fig 1b). Overlying the rising trend 
88 there are large year-to-year variations, as shown consistently by the $\sim 10 \mathrm{yr}$ Java tide gauge record

$89-$ the longest record along the Indonesian coast of the Indian Ocean ${ }^{29}$ - and satellite altimeter data

90 at the nearest location off the coast $(\sim 18 \mathrm{~km}$ southeast of the tide gauge; Fig $1 \mathrm{c})$. The altimeter

91 data detect ten extreme sea level events during the 26yr (1993-2018) period, with monthly mean

92 sea level anomalies (SLAs) exceeding two standard deviations $(0.26 \mathrm{~m})$. The tide gauge record

93 agrees exceptionally well with the altimeter data (correlation 0.99), albeit with somewhat larger

94 amplitudes ${ }^{30-32}$ likely because the tide gauge contains long-period tide signals but satellite

95 altimeter data removes them ${ }^{27}$. It is also possible that monthly tide gauge data includes signals of

96 storm surges, which cannot be adequately resolved by altimeter data. The good agreement

97 between satellite and tide gauge observations suggests that large-scale ocean circulation

98 dynamics dominate small-scale coastal processes in causing SLAs along Java coast, where the

99 shelf is narrow and continental slope is steep. Therefore, satellite altimeter data can well

100 represent Java coastal SLAs and can be used to detect sea level extremes in this region. The

101 SLAs along southern Sumatra coast are highly coherent with those of Java (supporting Fig S1).

102 Most strikingly, nine of the ten sea level extremes occur in the recent decade (2010-2017) with

103 only the weakest event occurring in 1998 during the entire $26 \mathrm{yr}$ altimeter period (Fig 1c). This

104 situation is more evident for a longer period of 1960-2017 using the European Centre for

105 Medium-Range Weather Forecasts (ECMWF) ocean analysis/reanalysis system 4 (ORAS4)

106 data $^{33}$ and ocean model simulations (supplementary Fig S2). Five of the ten are compounded by

107 marine heatwaves ${ }^{34}$ (defined in Methods), and four of the five C-HHEX events occur during

108 2010-2017 (Fig 1c and supplementary Table S1). The strongest compound event happened in

109 June 2016, when monthly mean sea level rose by $\sim 0.44 \mathrm{~m}(0.45 \mathrm{~m})$ from satellite (tide gauge)

110 observation and sea surface temperature (SST) warmed by $1.84^{\circ} \mathrm{C}(>99$ th percentile). This sea 
111 level magnitude is near the lower end of the $0.5-1 \mathrm{~m}$ amplitudes of tropical storm and high tide

112 surges on daily timescales with a return period of $100 \mathrm{yrs}$ along the Indonesian coasts ${ }^{5}$, where

113 storm impacts are relatively weak compared to higher-latitude coastal oceans ${ }^{35}$. While sea level

114 signals of the C-HHEX events can encompass the entire Southeast Asian coasts (Fig 2a), the

115 associated marine heatwaves are confined to Indonesian coast east of Sumatra and extend

116 hundreds of kilometers offshore (Fig 2c). By contrast, the sea level alone extremes without

117 marine heatwaves are overall weaker and confined to the Indonesian coasts (Figs 2b, 2d). Here,

118 we retain the seasonal cycle when identifying the extremes as in recent studies ${ }^{12,34,36}$ because

119 coastal inundation and marine ecosystems are sensitive to the full sea level and temperature

120 values.

121 Causes for sea level extremes To understand why extreme sea level events occur more

122 frequently in the past decade, we analyze the ORAS4 reanalysis data and ocean model

123 simulations from ROMS and HYCOM. Both the reanalysis data and model simulations well

124 capture the satellite observed SLAs near Java coast (correlation 0.95-0.98; Fig 1d), albeit with

125 some quantitative differences. The reanalysis data - which assimilated satellite altimeter data -

126 underestimate the rising trend and amplitudes of individual events, and more underestimations

127 are seen in HYCOM simulation (Fig 1d) partly due to the Indo-Pacific regional HYCOM with

128 closed boundary conditions cannot properly simulate global sea level rise. By contrast, ROMS

129 captures the full magnitudes of extreme events detected by altimeter data, with overestimation

130 for some events as in tide gauge observation (Figs 1c-1d, blue lines). This is likely because

131 ROMS, which is forced by 3hourly forcing fields, contains storm surge signals like the tide

132 gauge data. Due to the stronger amplitudes, more extremes are identified in tide gauge record

133 and ROMS simulation based on the $0.26 \mathrm{~m}$ threshold. However, the increased occurrence of 
134 extreme events in the past decade is evident in all datasets. Since this study aims to understand 135 long-lasting climate driven extremes, we focus on the events identified by monthly altimeter 136 observations. The high sea level events along southern Sumatra coast are highly coherent with 137 those of Java but with weaker amplitudes (Fig S1).

138 After removing the slowly varying decadal-to-interdecadal component, collectively referred to as 139 'decadal' hereafter, the pattern of increased occurrence disappears (Fig 3a and Supplementary 140 Fig S2), suggesting that it is the decadal SLAs of 0.1-0.2m during 2010-2017 that boosts up the 141 frequency of sea level extremes. The decadal SLAs consist of anthropogenically-induced global 142 sea level rise ${ }^{1,22}$ and internal climate variability (Fig 3a, red \& green lines). During the altimeter

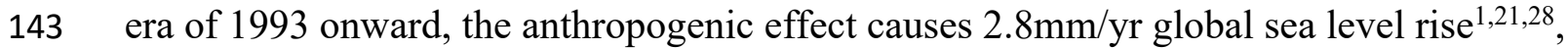
144 contributing $\sim 50 \%$ of the decadal SLAs of the past decade near Java coast. On a regional scale, 145 the impact of external forcing (natural plus anthropogenic) on dynamical sea level that excludes 146 global mean near Indonesian coast is weak $(<2 \mathrm{~cm})$ with large uncertainties ${ }^{37}$, based on the large 147 ensemble experiments of multiple CMIP6 models (supporting Fig S3).

148 For the internal decadal variability component, a combined invigoration of surface westerly 149 winds over the tropical Indian Ocean and easterly winds in the tropical Pacific, which represent 150 intensified Indian and Pacific Walker Cells (the atmospheric zonal overturning circulations over 151 tropical Indo-Pacific basin), is the main cause. The enhanced equatorial westerly surface winds 152 during 2010-2017 pile up water and thus increase sea level in the eastern basin; meanwhile, 153 strengthened northwesterly longshore winds of southern Sumatra and Java coasts cause surface 154 Ekman mass convergence toward the coasts and further enhance sea level there (Fig 4). Portions 155 of these winds, however, result from remote forcing by the Interdecadal Pacific Oscillation 
$156\left(\mathrm{IPO}^{38}\right)$, as suggested by the agreement between the wind-generated decadal SLA and climate 157 model simulations that isolate tropical Pacific sea surface temperature forcing using CESM1 (Fig 1583 b, solid blue and purple lines). During the global surface warming hiatus period of 2003-2012 159 when the easterly trade winds intensify in the tropical Pacific and the IPO is in its negative 160 phase ${ }^{39}$, the Pacific forcing is the major cause for the upward sea level trend, and wind stress 161 forcing alone cannot fully explain the rising rate (compare green, blue and purple lines of Fig $3 b$ ). 162 While the enhanced Indian Ocean westerly winds tend to reduce the Indonesian Throughflow 163 (ITF) from the Pacific to the Indian Ocean by increasing sea level on the Indian Ocean side (Fig 164 4), the dramatic strengthening of surface easterly trades intensifies sea level in western tropical 165 Pacific, causing unprecedented enhancement of the ITF during the hiatus period ${ }^{40-47}$. The 166 enhanced ITF mass and heat transports ${ }^{40-47}$ contribute to the decadal sea level rise along the 167 Indonesian coast from 2003-2012, with the effect of salinity being weak in this coastal area ${ }^{48}$. 168 The enhanced surface winds over the tropical Indian Ocean associated with monsoons and 169 especially those associated with decadal variability of the Indian Ocean Dipole (IOD ${ }^{49-51}$; Fig $3 b$, 170 dotted blue) account for the rise since 2012.

171 While anthropogenic forcing and internal decadal variability increased the frequency of 172 occurrence of sea level extremes in the past decade, what are the causes for individual events? 173 Experiments using ocean general circulation models and the Bayesian dynamical linear model 174 show that surface wind stress forcing is the deterministic cause for all extremes identified (Fig 3c; 175 supplementary Fig S4b). The equatorial westerly wind anomalies (Fig 2a) cause Ekman mass 176 convergence to the equator, raising sea level. The high sea level signals propagate eastward as 177 equatorial Kelvin waves, which subsequently propagate poleward as coastally trapped waves 178 upon impinging on the eastern boundary, inducing coherent sea level surges along the entire 
179 southeast Asian coasts (Fig 2a). Meanwhile, the local northwesterly longshore winds along

180 southern Sumatra and Java coasts induce coastal Ekman mass convergence, accumulate water to

181 Indonesian coast and enhance the remotely forced equatorial signals (Figs 2a-2b). The longshore 182 winds play important roles for some events especially for the sea level alone events (Figs $2 \mathrm{~b}$ and $1833 \mathrm{c})$.

184 For all of the five sea level alone events, the anomaly amplitudes evidently reduce when the 185 mean seasonal cycle is removed (Fig 3c, thick and thin black lines), suggesting that when 186 moderate interannual SLAs occur in the high sea level season of Indonesia in Dec-Mar, they can 187 cause severe coastal inundation (Figs 3c \& S4c; Table S1). By contrast, not all of the compound 188 events are aided by seasonal cycle. For instance, the strongest C-HHEX event of June 2016 189 occurred in the low sea level season of Indonesia, when southeasterly monsoon winds prevail 190 and the high SLA results entirely from interannual variability (Fig 3c; supporting Fig S5).

191 Compound Height-Heat EXtreme (C-HHEX) vs sea level alone events The five C-HHEXs all 192 occur during the years of negative IOD with four occurring with La Niña, the negative phase of 193 the El Niño-Southern Oscillation (ENSO'; Fig 3d and Table S1). The IOD and ENSO are the 194 dominant modes of interannual climate variability over the tropical Indo-Pacific basin, and they 195 are associated with basin-scale anomalies of atmospheric convection, surface wind and sea 196 surface temperature. Because IOD events generally develop in boreal summer and peak in Sep$197 \operatorname{Nov}^{49,50}$, they are phase-locked with the upwelling and low sea level season in the tropical 198 eastern Indian Ocean including the Indonesian coast (Figs 3c \& 5c, black curves), when 199 southeasterly trade winds cause Ekman transports that move the warmer surface water offshore, 200 shoal the thermocline and upwell colder subsurface water to the surface (supporting Figs S5 \& 
201

202

203

204

205

206

207

208

209

210

211

212

213

214

215

216

217

218

219

220

221

222

223

S6). With the precondition of shallow thermocline, the equatorial westerly and longshore northwesterly wind anomalies associated with the negative IOD - which are enhanced by La Niña for four of the five C-HHEX events - raise sea level (Fig 2a; supporting Fig S4b), deepen the thermocline (i.e. downwelling) and reduce cold water upwelling, causing large-amplitude interannual marine heatwaves and sea level extremes that last for several months (red curves of Figs 3c \& 5c; supporting Figs S5 \& S7). The importance of subsurface processes in causing the marine heatwaves is quantitatively assessed by the mixed layer heat budget analysis using ROMS output (Fig 5d). While the interannual warm anomalies are largely compensated by the seasonal cooling during July-October, they are less compensated or even enhanced by the seasonally warm temperatures and high sea levels during the IOD initiation (May-June) and decay (Nov-Dec) periods (Figs 3c, 5c \& S5-S7), causing the C-HHEX events near Indonesian coast (Figs 5a-5b). The warmer upper ocean may further increase sea level due to thermal expansion.

As a comparison, the five sea level alone events all occur during the Dec-March deep thermocline (i.e. downwelling) season. Even though the wind-driven coastal mass convergence still raises sea level, it does not apparently increase surface temperature due to the presence of a deep thermocline that reduces the sensitivity of sea surface temperature to changes in cold water upwelling rates (Figs 3c \& 5c; supporting Fig S8). These events are not associated with negative IOD or La Niña; rather, they are driven by the shorter lasting equatorial and longshore wind anomalies associated with Indian and Australian monsoon ${ }^{52,53}$, such as the $\sim 60$ intraseasonal oscillations that give rise to the January and March 2012 sea level events (Figs 3c-3d; supporting Fig S9). Indeed, winds associate with atmospheric intraseasonal oscillations ${ }^{54-56}$ also help intensify the sea level peak of June 2016 C-HHEX event (Fig S10) and significantly weaken the 
224 Indonesian Throughflow transport into the Indian Ocean from the Pacific ${ }^{57}$, further weakening 225 the already reduced Throughflow due to the negative $\mathrm{IOD}^{58}$. Since this paper focuses on long226 lasting extremes, the impacts of atmospheric intraseasonal oscillations will be investigated and 227 reported in a future research. Note that SLAs represent changes of mass and heat of the entire 228 water column, whereas sea surface temperature variability can be controlled by surface heating 229 process and is little affected by subsurface when thermocline is deep. Therefore, some marine 230 heatwave events are not associated with sea level extremes and vice versa.

231 The consistencies among tide gauge data, satellite observation, reanalysis product and various 232 model simulations demonstrate that the extreme sea level and C-HHEX events detected here 233 exceed data and model uncertainties. Satellite altimetry, which suffers from land contamination 234 near coasts, only provides data over the shelf away from the coasts. Yet, here the altimeter data 235 successfully represent and therefore are used to detect sea level extremes along Indonesian coast 236 of the Indian Ocean. This is because changes in large-scale ocean circulations driven by remote 237 and local winds - instead of local smaller scale shelf processes - determine the long-lasting sea 238 level extremes in this region. This result points to the importance of continued tide gauge and 239 satellite observations in detecting and understanding coastal sea level extremes in a changing 240 climate. The agreements among different models on the controlling mechanisms lend further 241 confidence in our results.

242 Our new results show that individual extreme events induced by strong intraseasonal-to243 interannual climate variability (monsoon, negative IOD and La Niña), their constructive 244 interferences, and interplay by decadal climate variability and global sea level rise generate the 245 long-lasting (> 1 month) extreme sea level and C-HHEX events along Indonesian coast with 246 frequent occurrence in the past decade. Climate model projections, however, suggest that 
247 continued anthropogenic warming will reduce the number of negative IOD events due to a mean

248 state change toward a shallower thermocline in the eastern pole and a deeper thermocline in the

249 western pole of the IOD ${ }^{59-61}$. Even though the deeper thermocline in the western pole could

250 weaken the magnitude of temperature anomalies and thus negative IOD index, the shallower

251 thermocline in the eastern pole - with continued global sea level rise and anthropogenic warming

252 albeit with a slower warming rate in this area ${ }^{60}$ - favorably preconditions the ocean for stronger

253 sea level extremes and C-HHEXs in coastal Indonesia, when forced by downwelling-favorable

254 winds associated with internal climate variability. This would aggravate the climate change

255 induced social, environmental and ecological stresses on Indonesia.

\section{Main References}

2571 Church, J. et al. Sea level change. Climate change 2013: the physical science basis.

258 Contribution of working group I to the fifth assessment report of the intergovernmental

259 panel on climate change. Cambridge University Press, Cambridge, United Kingdom and

260 New York, NY, USA, 1137-1216 (2013).

2612 Field, C. B. et al. in Climate change 2014: impacts, adaptation, and vulnerability. Part A:

262 global and sectoral aspects. Contribution of Working Group II to the Fifth Assessment

263 Report of the Intergovernmental Panel on Climate Change 1-32 (Cambridge

264 University Press, 2014).

2653 Oppenheimer, M. et al. Sea level rise and implications for low lying Islands, coasts and

$266 \quad$ communities. (2019).

2674 Sweet, W. W. V., Dusek, G., Obeysekera, J. \& Marra, J. J. Patterns and projections of

268 high tide flooding along the US coastline using a common impact threshold. (2018). 
2695 Muis, S., Verlaan, M., Winsemius, H. C., Aerts, J. C. \& Ward, P. J. A global reanalysis

270 of storm surges and extreme sea levels. Nature communications 7, 1-12 (2016).

2716 McPhaden, M. J., Zebiak, S. E. \& Glantz, M. H. ENSO as an integrating concept in earth 272 science. science 314, 1740-1745 (2006).

2737 Chelton, D. B. \& Davis, R. E. Monthly Mean Sea-Level Variability Along the West274 Coast of North-America. Journal of Physical Oceanography 12, 757-784, doi:Doi $275 \quad 10.1175 / 1520-0485(1982) 012<0757:$ Mmslva $>2.0 . C o ; 2$ (1982).

2768 Clarke, A. J. \& Vangorder, S. On Enso Coastal Currents and Sea Levels. Journal of 277 Physical Oceanography 24, 661-680, doi:Doi 10.1175/1520-

$278 \quad$ 0485(1994)024<0661:Oeccas $>2.0$. Co;2 (1994).

2799 Han, W. et al. Impacts of basin-scale climate modes on coastal sea level: a review. $280 \quad$ Surveys in geophysics 40, 1493-1541 (2019).

28110 Hamlington, B. D. et al. The effect of the El Nino-Southern Oscillation on US regional 282 and coastal sea level. Journal of Geophysical Research-Oceans 120, 3970-3986, 283 doi:10.1002/2014jc010602 (2015).

28411 Muis, S., Haigh, I. D., Guimarães Nobre, G., Aerts, J. C. \& Ward, P. J. Influence of El 285 Niño-Southern Oscillation on Global Coastal Flooding. Earth's Future 6, 1311-1322 $286 \quad$ (2018).

28712 Holbrook, N. J. et al. A global assessment of marine heatwaves and their drivers. Nature $288 \quad$ communications 10, 1-13 (2019).

28913 Gupta, A. S. et al. Drivers and impacts of the most extreme marine heatwaves events. $290 \quad$ Scientific reports 10, 1-15 (2020). 
29114 Holbrook, N. J. et al. Keeping pace with marine heatwaves. Nature Reviews Earth \& 292 Environment 1, 482-493 (2020).

29315 Ummenhofer, C. C. \& Meehl, G. A. Extreme weather and climate events with ecological 294 relevance: a review. Philosophical Transactions of the Royal Society B: Biological Sciences 372, 20160135 (2017).

29616 Stocker, T. et al. IPCC, 2013: summary for policymakers in climate change 2013: the 297 physical science basis, contribution of working group I to the fifth assessment report of 298 the intergovernmental panel on climate change. Camb. Univ. Press Camb. UKNY NY $299 \quad$ USA (2013).

30017 Zscheischler, J. et al. Future climate risk from compound events. Nature Climate Change $301 \quad 8,469-477(2018)$.

30218 Mukherjee, S. \& Mishra, A. K. Increase in Compound Drought and Heatwaves in a 303 Warming World. Geophysical Research Letters, e2020GL090617 (2020).

30419 Nicholls, N. et al. in Managing the risks of extreme events and disasters to advance 305 climate change adaptation 109-230 (Cambridge University Press Cambridge, UK, and $306 \quad$ New York, NY, USA, 2012).

30720 Group, W. Global sea-level budget 1993-present. Earth Syst. Sci. Data 10, 1551-1590 $308 \quad$ (2018).

$30921 \quad$ Nerem, R. S. et al. Climate-change-driven accelerated sea-level rise detected in the $310 \quad$ altimeter era. Proceedings of the National Academy of Sciences 115, 2022-2025 (2018).

31122 Chen, X. et al. The increasing rate of global mean sea-level rise during 1993-2014. Nature Climate Change 7, 492-495 (2017). 
31323 Shchepetkin, A. F. \& McWilliams, J. C. The regional oceanic modeling system (ROMS):

314 a split-explicit, free-surface, topography-following-coordinate oceanic model. Ocean $315 \quad$ modelling 9, 347-404 (2005).

31624 Bleck, R. An oceanic general circulation model framed in hybrid isopycnic-Cartesian 317 coordinates. Ocean Modell. 4, 55-88 (2002).

31825 Hurrell, J. W. et al. The community earth system model: a framework for collaborative 319 research. Bulletin of the American Meteorological Society 94, 1339-1360 (2013).

32026 Petris, G., Petrone, S. \& Campagnoli, P. in Dynamic Linear Models with R 31-84 $321 \quad$ (Springer, 2009).

32227 Taburet, G. et al. DUACS DT2018: 25 years of reprocessed sea level altimetry products. 323 (2019).

32428 Beckley, B. D., Callahan, P. S., Hancock III, D., Mitchum, G. \& Ray, R. On the 325 "Cal-Mode" Correction to TOPEX Satellite Altimetry and Its Effect on the Global Mean 326 Sea Level Time Series. Journal of Geophysical Research: Oceans 122, 8371-8384 (2017).

32729 Holgate, S. J. et al. New data systems and products at the permanent service for mean sea 328 level. Journal of Coastal Research 29, 493-504 (2013).

32930 Hamlington, B. et al. The effect of the El Niño-Southern Oscillation on US regional and 330 coastal sea level. Journal of Geophysical Research: Oceans 120, 3970-3986 (2015).

$33131 \quad$ Han, W. et al. in Integrative study of the mean sea level and its components 221-254 $332 \quad$ (Springer, 2017).

$333 \quad 32$ Iskandar, I., Mardiansyah, W., Masumoto, Y. \& Yamagata, T. Intraseasonal Kelvin 334 waves along the southern coast of Sumatra and Java. Journal of Geophysical Research: 335 Oceans 110 (2005). 
33633 Balmaseda, M. A., Mogensen, K. \& Weaver, A. T. Evaluation of the ECMWF ocean 337 reanalysis system ORAS4. Q. J. R. Meteorol. Soc. 139, 1132-1161 (2013).

33834 Hobday, A. J. et al. A hierarchical approach to defining marine heatwaves. Progress in $339 \quad$ Oceanography 141, 227-238 (2016).

34035 Knapp, K. R., Kruk, M. C., Levinson, D. H., Diamond, H. J. \& Neumann, C. J. The 341 international best track archive for climate stewardship (IBTrACS) unifying tropical 342 cyclone data. Bulletin of the American Meteorological Society 91, 363-376 (2010).

$343 \quad 36$ Oliver, E. C. et al. Longer and more frequent marine heatwaves over the past century. 344 Nature communications 9, 1-12 (2018).

34537 Carson, M. et al. Coastal sea level changes, observed and projected during the 20th and 346 21st century. Climatic Change 134, 269-281 (2016).

34738 Power, S., Casey, T., Folland, C., Colman, A. \& Mehta, V. Inter-decadal modulation of 348 the impact of ENSO on Australia. Climate Dyn. 15, 319-324 (1999).

34939 Xie, S.-P. Oceanography: Leading the hiatus research surge. Nature Climate Change 6, $350 \quad 345-346(2016)$.

$35140 \quad$ Lee, S.-K. et al. Pacific origin of the abrupt increase in Indian Ocean heat content during 352 the warming hiatus. Nature Geosci 8, 445-449, doi:10.1038/ngeo2438

353 http://www.nature.com/ngeo/journal/v8/n6/abs/ngeo2438.html\#supplementary-information $354 \quad$ (2015).

$35541 \quad$ Nieves, V., Willis, J. K. \& Patzert, W. C. Recent hiatus caused by decadal shift in Indo356 Pacific heating. Science 349, 532-535, doi:10.1126/science.aaa4521 (2015). 
35742 Dong, L. \& McPhaden, M. J. Interhemispheric SST gradient trends in the Indian Ocean prior to and during the recent global warming hiatus. Journal of Climate 29, 9077-9095 (2016).

36043 Desbruyères, D., McDonagh, E. L., King, B. A. \& Thierry, V. Global and full-depth ocean temperature trends during the early twenty-first century from argo and repeat hydrography. Journal of Climate 30, 1985-1997 (2017).

36344 Cheng, L. et al. Improved estimates of ocean heat content from 1960 to 2015. Science $364 \quad$ Advances 3, e1601545 (2017).

36545 Li, Y., Han, W. \& Zhang, L. Enhanced decadal warming of the southeast Indian Ocean 366 during the recent global surface warming slowdown. Geophysical Research Letters 44, 367 9876-9884 (2017).

36846 Li, Y., Han, W., Hu, A., Meehl, G. A. \& Wang, F. Multidecadal changes of the upper 369 Indian Ocean heat content during 1965-2016. Journal of Climate 31, 7863-7884 (2018).

37047 Zhang, Y. et al. Strengthened Indonesian throughflow drives decadal warming in the 371 Southern Indian Ocean. Geophysical Research Letters 45, 6167-6175 (2018).

37248 Llovel, W. \& Lee, T. Importance and origin of halosteric contribution to sea level change 373 in the southeast Indian Ocean during 2005-2013. Geophysical Research Letters 42, 1148374 1157, doi:10.1002/2014g1062611 (2015).

37549 Saji, N., Goswami, B., Vinayachandran, P. \& Yamagata, T. A dipole mode in the tropical $376 \quad$ Indian Ocean. Nature 401, 360-363 (1999).

$37750 \quad$ Webster, P. J., Moore, A. M., Loschnigg, J. P. \& Leben, R. R. Coupled ocean378 atmosphere dynamics in the Indian Ocean during 1997-98. Nature 401, 356-360 (1999). 
37951 Ashok, K., Chan, W.-L., Motoi, T. \& Yamagata, T. Decadal variability of the Indian Ocean dipole. Geophys. Res. Lett. 31, L24207, doi:10.1029/2004g1021345 (2004).

$38152 \quad$ Webster, P. J. \& Yang, S. Monsoon and ENSO: Selectively interactive systems. Quarterly Journal of the Royal Meteorological Society 118, 877-926 (1992).

38353 Kajikawa, Y., Wang, B. \& Yang, J. A multi-time scale Australian monsoon index. International Journal of Climatology 30, 1114-1120 (2010).

38554 Madden, R. A. \& Julian, P. R. Detection of a 40-50 day oscillation in the zonal wind in 386 the tropical Pacific. J. Atmos. Sci. 28, 702-708 (1971).

38755 Lau, W. K., Waliser, D. E., Sperber, K., Slingo, J. \& Inness, P. Modeling intraseasonal 388 variability. Intraseasonal Variability in the Atmosphere-Ocean Climate System, 399-431 389 (2012).

39056 Zhang, C. Madden-julian oscillation. Rev. Geophys. 43, RG2003, 391 doi:10.1029/2004RG000158 (2005).

39257 Napitu, A. M., Pujiana, K. \& Gordon, A. L. The Madden-Julian Oscillation's impact on 393 the Makassar Strait surface layer transport. Journal of Geophysical Research: Oceans 394 124, 3538-3550 (2019).

39558 Pujiana, K., McPhaden, M. J., Gordon, A. L. \& Napitu, A. M. Unprecedented response of 396 Indonesian throughflow to anomalous Indo-Pacific climatic forcing in 2016. Journal of 397 Geophysical Research: Oceans 124, 3737-3754 (2019).

39859 Abram, N. J. et al. Palaeoclimate perspectives on the Indian Ocean Dipole. Quaternary 399 Science Reviews 237, 106302 (2020).

40060 Cai, W. et al. Stabilised frequency of extreme positive Indian Ocean Dipole under 1.5 C 401 warming. Nature communications 9, 1419 (2018). 
61 Cai, W. et al. Increased frequency of extreme Indian Ocean Dipole events due to

403 greenhouse warming. Nature 510, 254-258, doi:10.1038/nature13327 (2014).

404 
Figure 1: Trend map and timeseries of satellite-observed sea level, surface wind, and sea surface

407 temperature (SST) and a tide gauge record at Java coast, marked by "o" in a and $\mathbf{b}$. a, Linear trend of 408 satellite sea level and cross-calibrated multiplatform (CCMP) surface wind stress from 1993-2018. b,

409 Linear trend of satellite SST for 1993-2018. c, Time series of monthly mean sea level anomaly (SLA)

410 from tide gauge station Cilacap B during 2007-2016 (blue curve); data from Permanent Service for Mean

411 Sea Level, 2020 after correction for Glacial Isostatic Adjustment and inverted barometer effect) and from

412 the multiple-satellite-merged altimeter data at the nearest grid point (black). The SLAs are relative to a

413 60yr mean (1958-2017) of ECMWF Ocean Reanalysis System 4 (ORAS4) data at the nearest location.

414 Values exceeding 2 standard deviations (STD) of altimeter data (horizontal blue line) are identified as

415 extreme events (indicated by vertical-dotted lines). Red dotted lines indicate sea level extremes

416 cooccurred with marine heatwaves, dubbed Compound Height and Heat EXtremes (C-HHEX) events. d,

417 Monthly SLAs from satellite (black, same as that of c), ORAS4 reanalysis data (red), simulations from

418 two independent ocean general circulation models: ROMS and HYCOM (blue and green). See methods

419 for data and models.

420 Figure 2. Composite of satellite-observed monthly sea level anomaly (SLA), surface wind stress anomaly,

421 and sea surface temperature anomaly (SSTA) for the peak months of five compound height and heat

422 extremes (C-HHEX) and five sea level alone extreme events. All anomalies are relative to 1993-2018

423 mean. a \& b, Composites of SLA (color) and surface wind stress (arrows) for C-HHEX and sea level

424 events; $\mathbf{c} \& \mathbf{d}$, The same as a \& b but for their corresponding SSTA and surface wind stress. Wind

425 vectors are the average for the event peak month and the preceding month, considering the propagation

426 time of equatorial Kelvin waves that impact SLA and SSTA.

427 Figure 3. Time series of monthly sea level anomalies (SLAs) averaged over Java coastal area

428 (Supplementary Fig S2), anthropogenically-induced global mean sea level rise (GMSLR) and climate 
indices. Calculations are done for 1960-2017 period but only 1993-2017 is shown for clarity. The 19602017 mean is removed from each series. a, ROMS simulated total SLA (black), anthropogenic GMSLR (red), ROMS natural decadal SLA (8yr lowpass filtered with anthropogenic GMSLR removed; green), and ROMS seasonal-to-interannual SLA (blue). b, ROMS decadal SLA (green), SLA caused by remote equatorial wind and local longshore wind assessed from Bayesian Dynamic Linear Model (DLM; blue), SLA from the 10-member ensemble mean of Pacific Pacemaker experiment using Community Earth System Model version 1 (CESM1) - assessing the impacts of tropical Pacific sea surface temperature anomaly (purple) - and index of the Interdecadal Pacific Oscillation (IPO; dotted purple). Labels on the right indicate normalized indices of IPO and decadal variability of Indian Ocean Dipole (IOD). Decadal variability of Indian and Australian-Indonesian monsoon winds follow IPO index and thus not shown. c, ROMS seasonal-to-interannual SLA (think black), interannual SLA with seasonal variability removed (thick black), interannual SLA forced by remote equatorial and local longshore winds (red), and SLA forced only by remote equatorial wind (blue). d, Normalized indices of the E1 Niño-Southern Oscillation (ENSO; red), IOD (blue), Indian monsoon wind index (black; one month lead) and Australian-Indonesian monsoon index (green). See Methods for more details.

Figure 4. Internal decadal (8yr lowpass filtered) anomalies of surface wind stress (arrows) and sea level (color) averaged for 2010-2017, based on the monthly JRA55-do reanalysis winds that force the ROMS (see methods) and ROMS simulated SLAs relative to the 1960-2017 mean. Linear trend of winds and anthropogenic global mean sea level are removed before we apply the 8yr lowpass filter.

Figure 5. Composites of ROMS simulated sea surface temperature anomaly (SSTA) and surface wind anomalies (from JRA55-do reanalysis data that force ROMS) for the five C-HHEXs and time series of SSTA averaged in Java coastal area (Fig S2). a, Composite SSTA (color) and surface wind (arrows) anomalies with the 1993-2017 mean removed but seasonal variability 
453 retained to be consistent with Fig 2 from observations. b, The same as a but with seasonal

454 variability removed. c, Timeseries of mean seasonal variability (black) and variability with

455 seasonal anomaly removed which primarily represents interannual variability (red). d, Terms of

456 heat budget analysis for SSTA (red curve in b): time changing rate of SSTA from all processes

457 (dT/dt, black), from net surface heat flux (blue), from subsurface processes (upwelling+mixing,

458 red) and horizontal advection+mixing (green). Units: degree per month. 

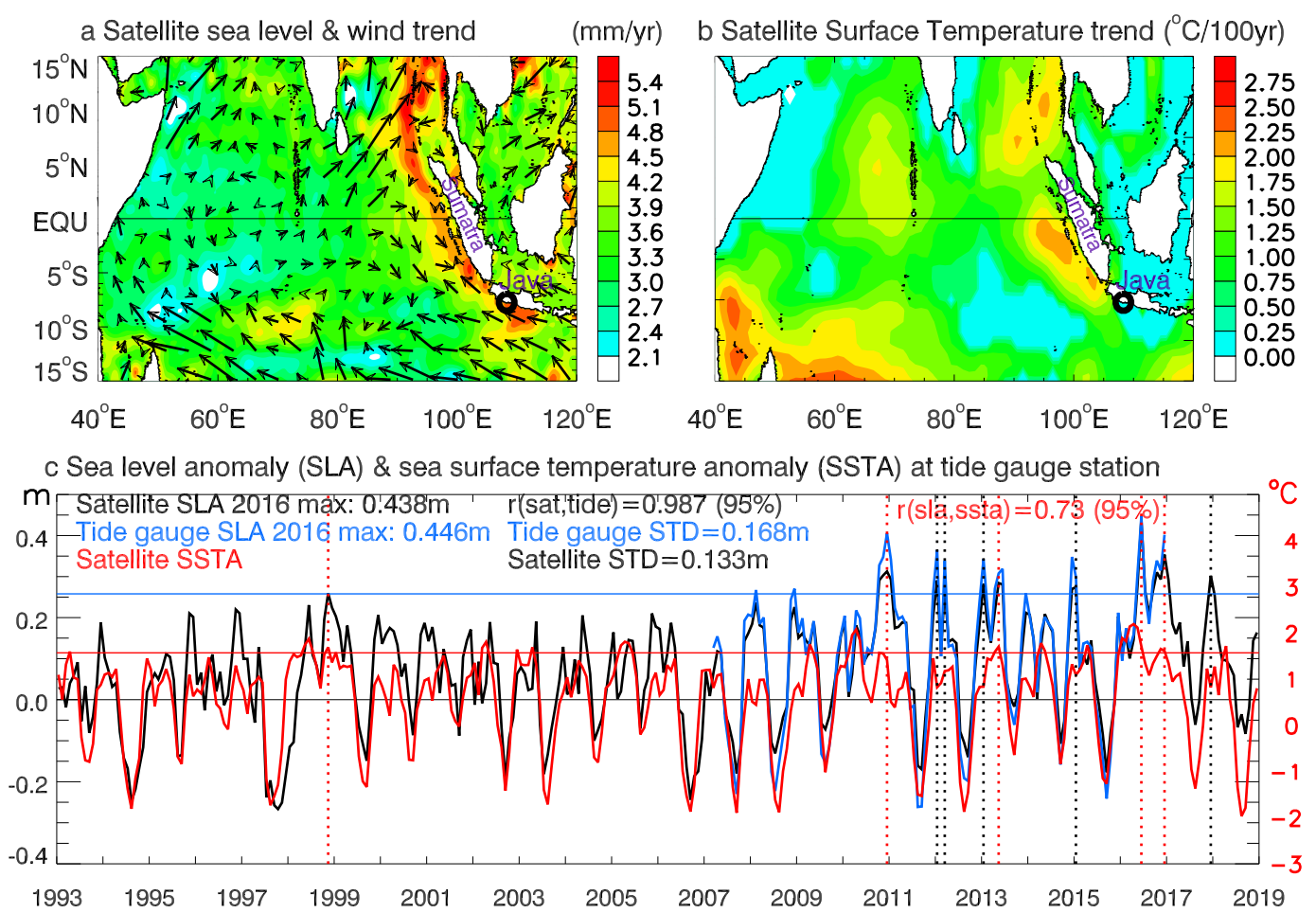

d Satellite observed \& model simulated SLA

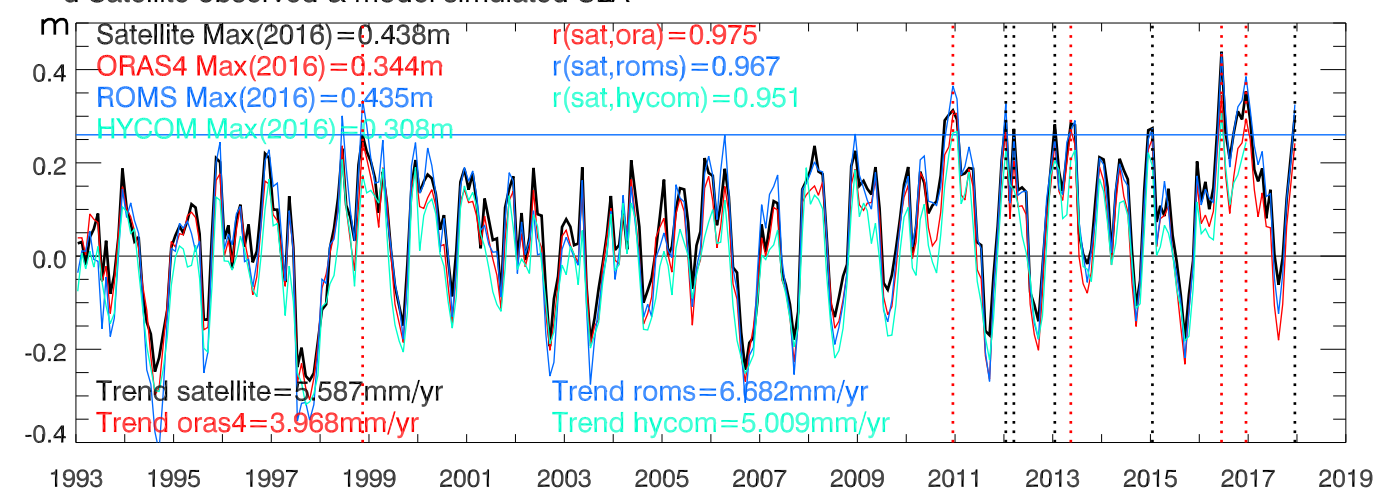

Figure 1: Trend map and timeseries of satellite-observed sea level, surface wind, and sea surface temperature (SST) and a tide gauge record at Java coast, marked by "o" in $\mathbf{a}$ and $\mathbf{b}$. $\mathbf{a}$, Linear trend of satellite sea level and cross-calibrated multiplatform (CCMP) surface wind stress from 1993-2018. b, Linear trend of satellite SST for 1993-2018. c, Time series of monthly mean sea level anomaly (SLA) from tide gauge station Cilacap B during 2007-2016 (blue curve); data from Permanent Service for Mean Sea Level, 2020 after correction for Glacial Isostatic Adjustment and inverted barometer effect) and from the multiple-satellite-merged altimeter data at the nearest grid point (black). The SLAs are relative to a $60 \mathrm{yr}$ mean (1958-2017) of ECMWF Ocean Reanalysis System 4 (ORAS4) data at the nearest location. Values exceeding 2 standard deviations (STD) of altimeter data (horizontal blue line) are identified as extreme events (indicated by vertical-dotted lines). Red dotted lines indicate sea level extremes cooccurred with marine heatwaves, defined as SSTA exceeding $90^{\text {th }}$ percentile (horizontal red line). These events are dubbed Compound Height and Heat EXtremes (C-HHEX). d, Monthly SLAs from satellite (black, same as that of c), ORAS4 reanalysis data (red), simulations from two independent ocean general circulation models: ROMS and HYCOM (blue and green). See methods for data and models. 

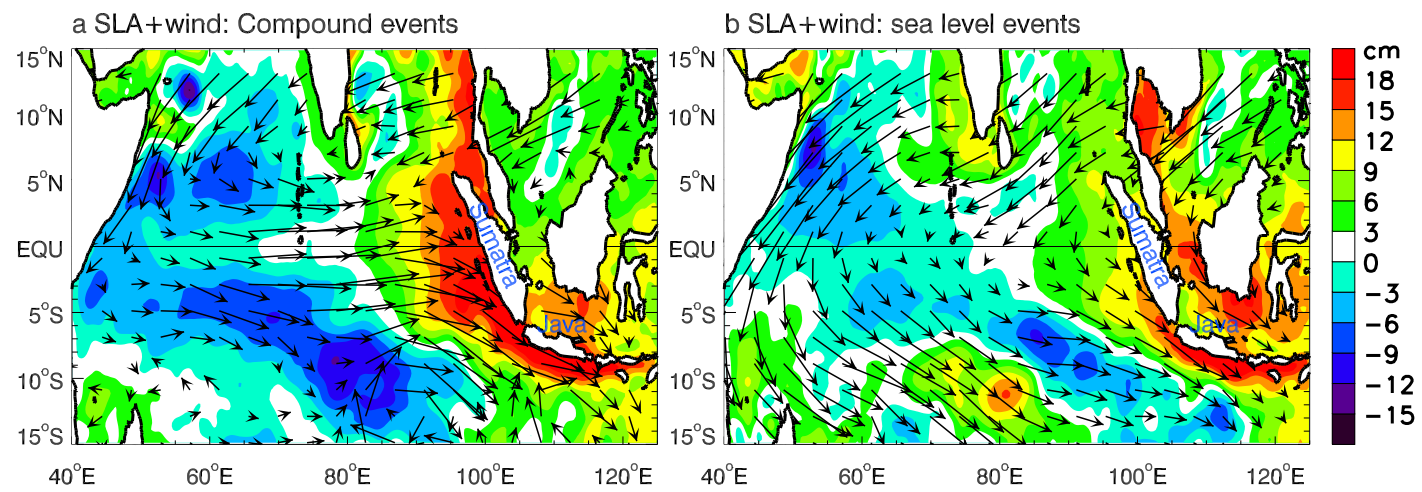

c SSTA+ wind: compound events

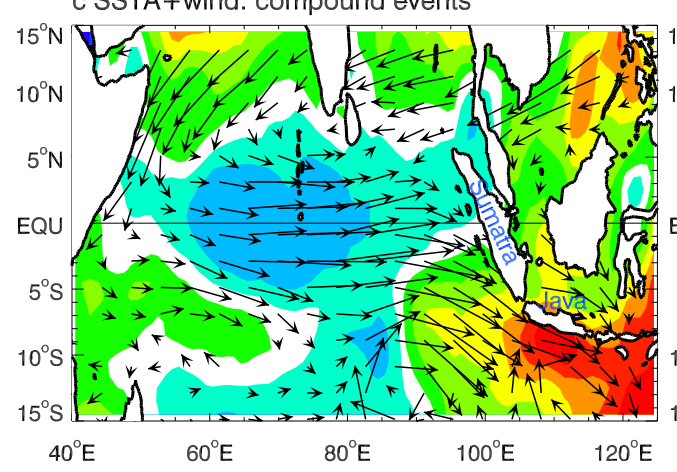

d SSTA+wind: sea level events

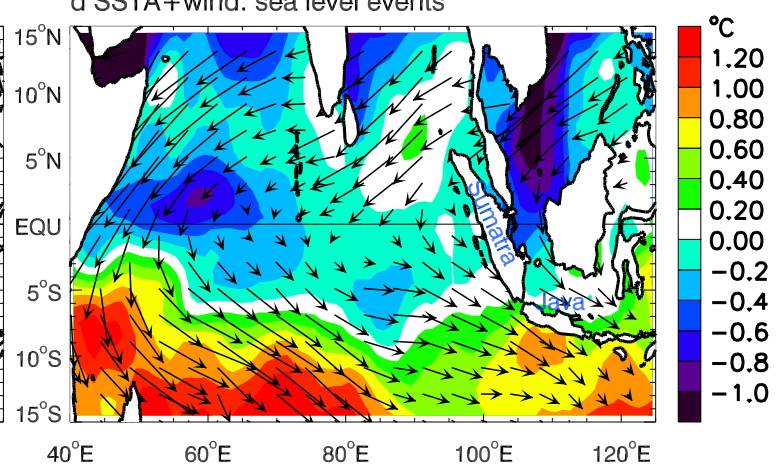

478 Figure 2. Composite of satellite-observed monthly sea level anomaly (SLA), surface wind stress anomaly,

479 and sea surface temperature anomaly (SSTA) for the peak months of five compound height and heat extremes (C-HHEX) and five sea level alone extreme events. All anomalies are relative to 1993-2018

481 mean. a \& b, Composites of SLA (color) and surface wind stress (arrows) for C-HHEX and sea level events; c \& d, The same as a \& b but for their corresponding SSTA and surface wind stress. Wind vectors are the average for the event peak month and the preceding month, considering the propagation time of equatorial Kelvin waves that impact SLA and SSTA. 
a ROMS SLA \& anthro GMSL: Java coast area mean

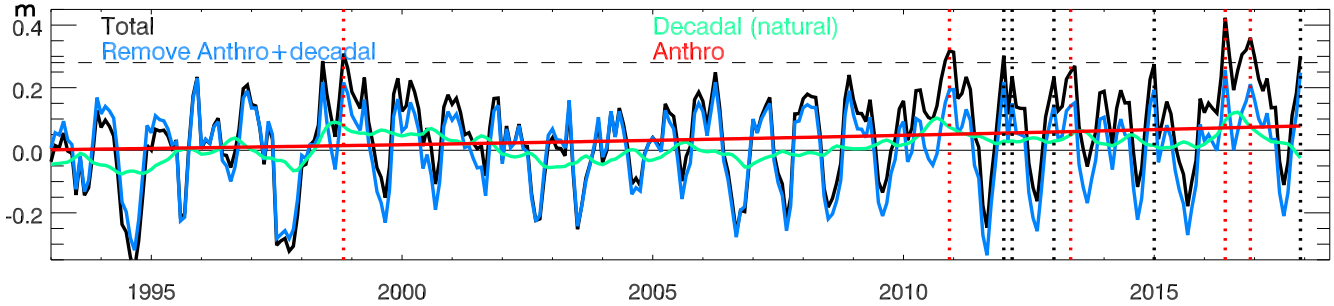

b Decadal SLA: ROMS \& CESM1 Pacific forcing

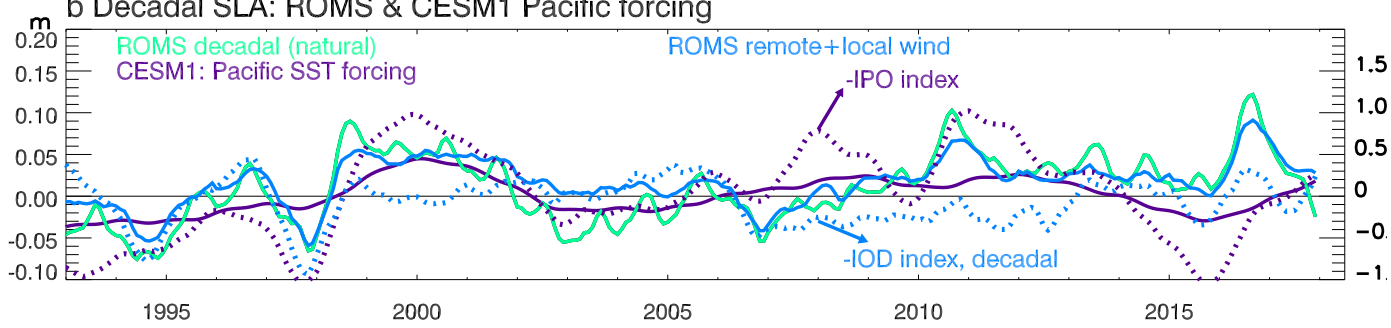

c ROMS season+interannual SLA: Remote \& Local wind forcing

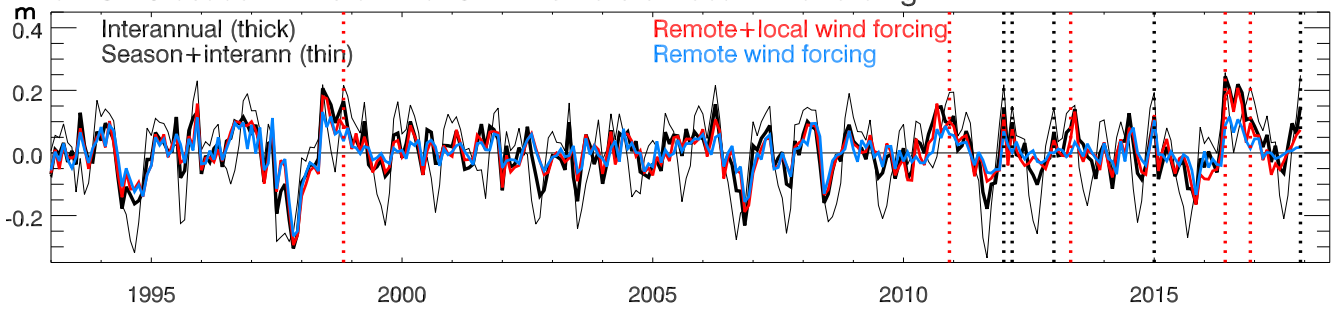

d Normalized climate indices

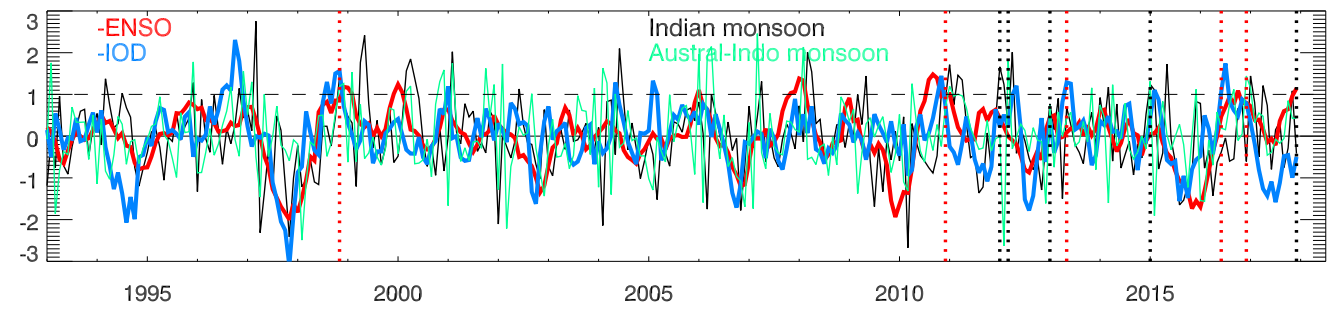

Figure 3. Time series of monthly sea level anomalies (SLAs) averaged over Java coastal area (Supplementary Fig S2), anthropogenically-induced global mean sea level rise (GMSLR) and climate indices. Calculations are done for 1960-2017 period but only 1993-2017 is shown for clarity. The 1960-2017 mean is removed from each series. a, ROMS simulated total SLA (black), anthropogenic GMSLR (red), ROMS natural decadal SLA (8yr lowpass filtered with anthropogenic GMSLR removed; green), and ROMS seasonal-to-interannual SLA (blue). b, ROMS decadal SLA (green), SLA caused by remote equatorial wind and local longshore wind assessed from Bayesian Dynamic Linear Model (DLM; blue), SLA from the 10-member ensemble mean of Pacific Pacemaker experiment using Community Earth System Model version 1 (CESM1) - assessing the impacts of tropical Pacific sea surface temperature anomaly (purple) - and index of the Interdecadal Pacific Oscillation (IPO; dotted purple). Labels on the right indicate normalized indices of IPO and decadal variability of Indian Ocean Dipole (IOD; dotted blue). Decadal variability of Indian and Australian-Indonesian monsoon winds follow IPO index and thus not shown. c, ROMS seasonal-to-interannual SLA (think black), interannual SLA with seasonal variability removed (thick black), interannual SLA forced by remote equatorial and local longshore winds (red), and SLA forced only by remote equatorial wind (blue). d, Normalized indices of the El Niño-Southern Oscillation (ENSO; red), IOD (blue), Indian monsoon wind index (black; one month lead) and Australian-Indonesian monsoon index (green). See Methods for more details. 


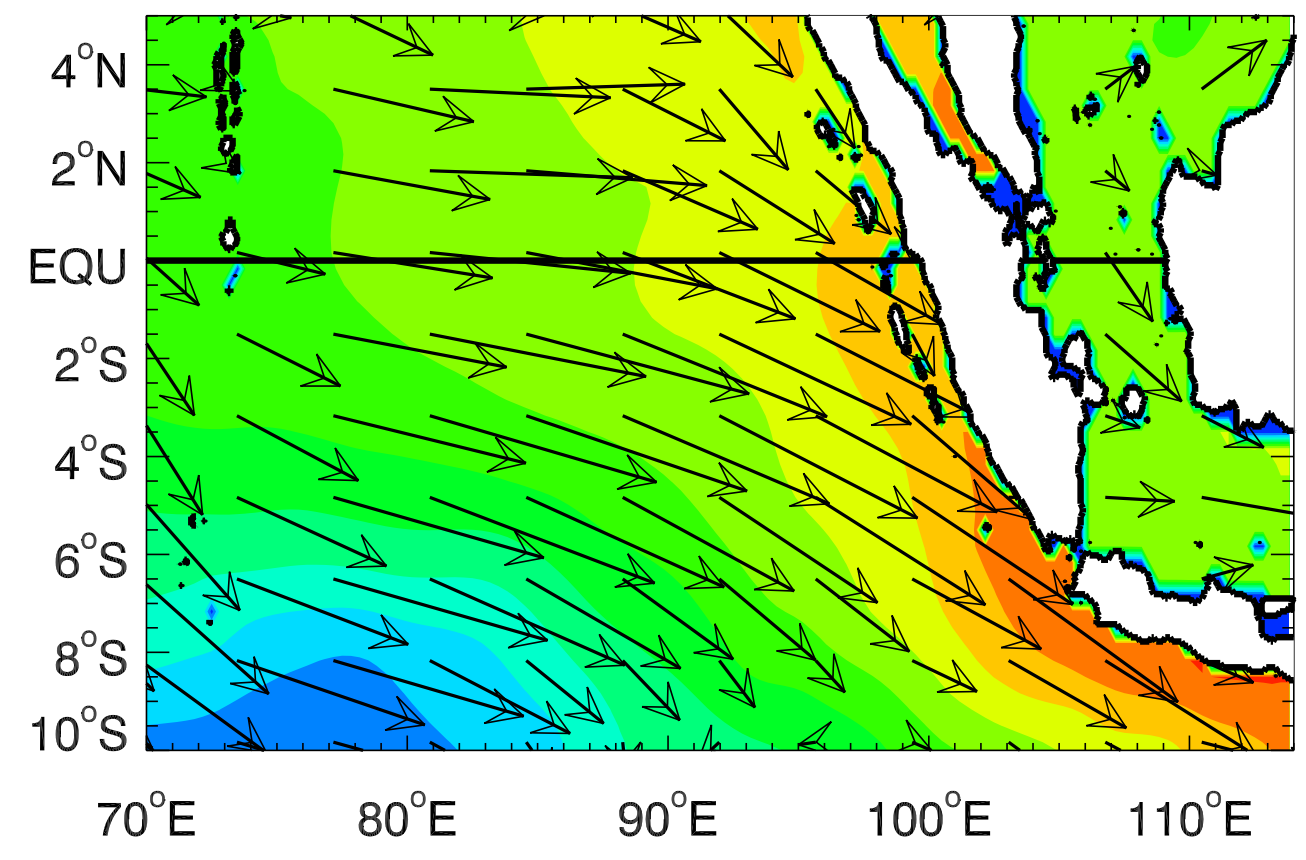

504

505 Figure 4. Internal decadal (8yr lowpass filtered) anomalies of surface wind stress (arrows) and 506 sea level (color) averaged for 2010-2017, based on the monthly JRA55-do reanalysis winds that

507 force the ROMS (see methods) and ROMS simulated SLAs relative to the 1960-2017 mean.

508 Linear trend of winds and anthropogenic global mean sea level are removed before we apply the 509 8yr lowpass filter. 

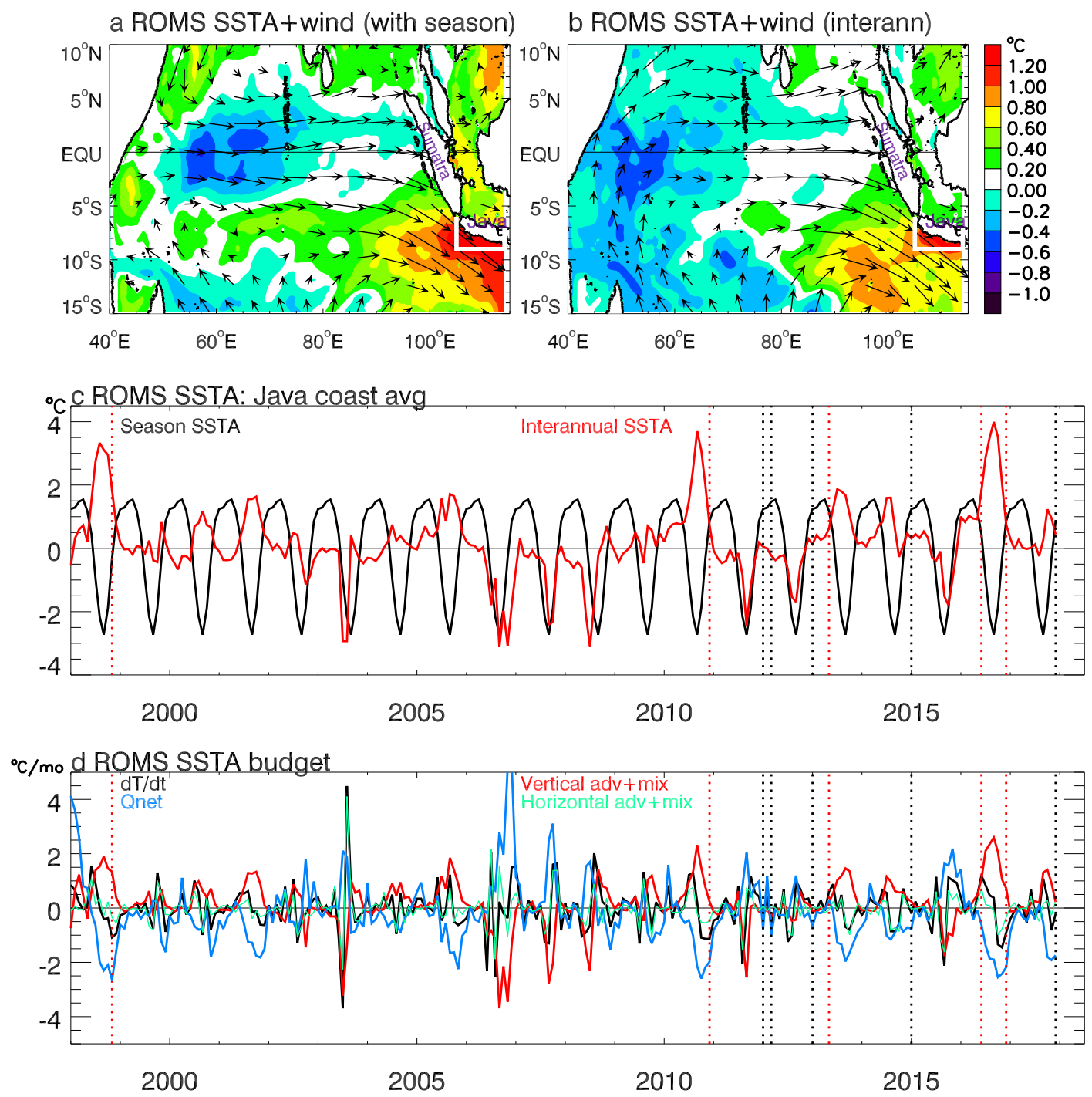

Figure 5. Composites of ROMS simulated sea surface temperature anomaly (SSTA) and surface wind anomalies (from JRA55-do reanalysis data that force ROMS) for the five C-HHEXs and time series of SSTA averaged in Java coastal area (Fig S2). a, Composite SSTA (color) and surface wind (arrows) anomalies with the 1993-2017 mean removed but seasonal variability retained to be consistent with Fig 2 from observations. b, The same as a but with seasonal cycle

518 removed. c, Timeseries of mean seasonal variability (black) and variability with seasonal

519 anomaly removed which primarily represents interannual variability (red). d, Terms of the mixed 520 layer heat budget analysis for SSTA (red curve in $\mathbf{b}$ ): time changing rate of SSTA from all 521 processes (dT/dt, black), from net surface heat flux (blue), from subsurface processes

522 (upwelling+mixing, red) and horizontal advection+mixing (green). Units: degree per month. 


\section{Methods}

525 Tide gauge data, satellite observations and ocean reanalysis product

526

527 The tide gauge data ${ }^{29}$ at station Calicap B of Java coast from 2007-2016 were downloaded from

528 the Permanent Service for Mean Sea Level (PSMSL) 2020:

529 https://www.psmsl.org/data/obtaining/, and were corrected for Glacial Isostatic Adjustment

530 (GIA) and Inverted Barometer (IB) effects that were provided by PSMSL along with the tide 531 gauge data. No land movement correction was done due to the lack of GPS data within 10km of

532 the tide gauge station ${ }^{62}$.

533 The satellite altimeter data ${ }^{27}$ (both two-satellite and all-satellite) were download from Copernicus 534 Climate Change Service (C3S) (2018): Sea level daily gridded data for the global ocean from 5351993 to present, European Union, under license agreement V1.2 (Nov 2019),

536 https://cds.climate.copernicus.eu/cdsapp\#!/dataset/satellite-sea-level-global?tab=overview.

537 Monthly mean of the all-satellite data are used in Figure 1, and the timeseries shown in Figure 1c 538 is from the nearest grid point approximately $18 \mathrm{~km}$ southeast of the Java tide gauge station. Using 539 the two-satellite data yields similar results except for slightly weaker amplitudes for some 540 extreme events.

541 The Cross-Calibrated Multi-Platform (CCMP) Satellite derived winds ${ }^{63,64}$ were downloaded 542 from http://www.remss.com/measurements/ccmp/. The National Oceanic and Atmospheric 543 Administration (NOAA) blended satellite sea surface temperature (SST) data ${ }^{65}$ are publicly 544 available at: https://psl.noaa.gov/data/gridded/data.noaa.oisst.v2.highres.html.

545 The European Centre for Medium-Range Weather Forecasts (ECMWF) operational ocean 546 analysis/reanalysis system version 4 (ORAS4) ${ }^{33}$ monthly sea level and temperature data, which 
547 are used to infer thermocline depth (the depth of $20^{\circ} \mathrm{C}$ isotherm), from 1958-2017 are obtained 548 from https://www.ecmwf.int/en/research/climate-reanalysis/ocean-reanalysis. The ORAS4 data 549 are ocean model hindcasts assimilated observational data, including satellite altimeter data.

\section{Estimates of anthropogenic global sea level rise}

551 First, we obtained the monthly global mean sea level (GMSL) data from CSIRO available for 552 1880-2013 22 (ftp://ftp.csiro.au/legresy/gmsl_files). Then we combine this dataset from 1880-

5531992 with NASA monthly GMSL data from 1993-2019² downloaded from

554 http://podaac.jpl.nasa.gov/dataset/MERGED TP J1 OSTM OST ALL V42 ${ }^{66}$ and choose the 555 1960-2019 period. Two methods were used to assess the anthropogenic GMSL rise (GMSLR):

556 (1) Since anthropogenic effect (thermal expansion, land ice melting and land water storage) 557 explains $\sim 90 \%$ of the GMSL in recent decades ${ }^{1,67}$, we use $90 \%$ of the quadratic fits of GMSL 558 (i.e., fitted GMSLR*0.9) to represent anthropogenic GMSLR; the quadratic fits are done 559 individually for the 1960-1992 and 1993-2019 periods to consider SLR acceleration in recent 560 decades; (2) For the 1993-2019 satellite period, we use the climate-change induced acceleration

561 of $0.084 \mathrm{~mm} \mathrm{yr}^{-2} 21$ to estimate the anthropogenic GMSLR, and keep the 1960-1992 period the 562 same as in (1). The two curves are almost identical.

\section{CMIP6 climate model simulations}

564 The coupled model intercomparison project phase 6 (CMIP6) large ensemble experiment results, 565 with ensemble members of each model ranging from 10-50 (Supporting Figure S3), were 566 obtained from https://esgf-node.IInl.gov/projects/cmip6/. 
569 The monthly HadISST data available since $1870^{68}$ are used to calculate climate mode indices.

570 The climatological seasonal cycle is removed before we calculate the indices. Climate events are

571 defined as indices exceeding one standard deviation. The Niño3.4 index, which is the timeseries

572 of SST anomaly (SSTA) averaged for $\left(120^{\circ} \mathrm{W}-170^{\circ} \mathrm{W}, 5^{\circ} \mathrm{S}-5^{\circ} \mathrm{N}\right)$, is used to represent ENSO.

573 ENSO is the most dominant mode of climate variability, which is associated with strong SSTA

574 in the tropical Pacific Ocean and has large impacts on global climate. It develops during boreal

575 summer and peaks during boreal winter (Dec-Feb). Its negative (cold) phase is referred to as La

576 Niña, and positive (warm) phase is called El Niño.

577 The tripole index ${ }^{69}$ of the Interdecadal Pacific Oscillation (IPO), is defined as the difference 578 between SSTA averaged in the equatorial basin $\left(10^{\circ} \mathrm{S}-10^{\circ} \mathrm{N}, 170^{\circ} \mathrm{E}-90^{\circ} \mathrm{W}\right)$ subtracts the SSTA 579 average between the north Pacific $\left(25^{\circ} \mathrm{N}-45^{\circ} \mathrm{N}, 140^{\circ} \mathrm{E}-145^{\circ} \mathrm{W}\right)$ and south Pacific $\left(50^{\circ} \mathrm{S}-15^{\circ} \mathrm{S}\right.$, $580150^{\circ} \mathrm{E}-160^{\circ} \mathrm{W}$ ) regions. The IPO is highly correlated with decadal variability of $\mathrm{ENSO}^{70}$, with

581 its negative phase being referred to as La Niña-like and positive (warm) phase being El Niño-like 582 SSTA pattern.

583 The dipole mode index, defined as the SSTA difference between tropical western Indian Ocean $584\left(50^{\circ} \mathrm{E}-70^{\circ} \mathrm{E}, 10^{\circ} \mathrm{S}-10^{\circ} \mathrm{N}\right)$ and tropical eastern Indian Ocean $\left(90^{\circ} \mathrm{E}-110^{\circ} \mathrm{E}, 0^{\circ}-10^{\circ} \mathrm{S}\right)$, represents 585 the Indian Ocean Dipole $\left(\mathrm{IOD}^{49}\right)$. In general the IOD develops in boreal summer and peaks 586 during boreal fall (Sep-Nov). Its negative phase is associated with warm SSTA and deeper 587 thermocline in the eastern pole and cold SSTA and shallower thermocline in the western pole.

588 The monthly wind shear index ${ }^{52}$ is used to represent Indian monsoon variability, which is the 589 zonal wind $\mathrm{U}$ at $850 \mathrm{hPa}(\mathrm{U} 850)$ averaged over $\left(40^{\circ} \mathrm{E}-110^{\circ} \mathrm{E}, \mathrm{EQ}-20^{\circ} \mathrm{N}\right)$ subtracts that of $200 \mathrm{hPa}$ 
591 index ${ }^{53}$ is defined as U850 anomaly averaged over $\left(110^{\circ} \mathrm{E}-130^{\circ} \mathrm{E}, 15^{\circ} \mathrm{S}-5^{\circ} \mathrm{S}\right)$. Both are calculated 592 from NCEP1 reanalysis winds ${ }^{71}$. Decadal variability of the Indian monsoon index is highly 593 correlated with the IPO index, with correlation coefficient $r=0.68(>95 \%)$ for the $1960-2017$ 594 period. The Australian-Indonesian monsoon is also significantly correlated with the IPO, with $595 \mathrm{r}=0.42(>95 \%)$ from $1960-2017$. The decadal variability of IOD $^{51}$ however is independent of the 596 IPO with $\mathrm{r}<0.1^{72,73}$.

597 The NOAA blended satellite SST data ${ }^{65}$ are used to detect marine heatwaves (MHWs). The 598 MHWs are defined as SST anomalies exceeding 90th percentile for a 30yr baseline period of 599 1990-2019, following previous studies on MHWs ${ }^{12,34,36}$. Based on this definition, mean seasonal 600 cycle is retained when identify MHW events; this is because marine ecosystems are sensitive to 601 the full variability magnitudes.

602 Ocean general circulation model (OGCM) and coupled climate model experiments

603 Two OGCMs were used to carry out experiments: The HYbrid Coordinate Ocean Model $604\left(\mathrm{HYCOM}^{24}\right)$ and the Regional Ocean Modeling System $\left(\mathrm{ROMS}^{23}\right)$. A recent version of HYCOM 605 was set up for the Indo-Pacific basin $\left(19^{\circ} \mathrm{E}-68^{\circ} \mathrm{W}, 55^{\circ} \mathrm{S}-50^{\circ} \mathrm{N}\right)$ with 35 hybrid layers and $1 / 3^{\circ}$ 606 resolution in tropical \& subtropical basins and gradually transiting to $1^{\circ}$ in middle-high latitudes. 607 Closed boundary conditions are used in the open ocean regions at northern, southern and part of 608 western boundaries where $5^{\circ}$ sponge layers are applied to relax model temperature and salinity to 609 WOA13 monthly climatology. Two experiments were performed for the 1940-2016 period, 610 forced with daily ERA-20 $0^{\text {th }}$ century reanalysis from 1940-2010 and ERA-Interim fields from 611 2011-2016 45,46,74: HYCOM main run (MR) \& HYCOM EXP run. The MR is the complete 
612 solution, and the EXP run is the same as the MR except for fixing the forcing fields used to 613 calculate heat and freshwater fluxes to their climatology but keeping daily wind stress forcing as 614 in the MR. Solutions from EXP isolates wind stress-driven sea level and SST variability. Due to 615 the closed boundaries in open ocean areas, global sea level rise is not properly represented and 616 thus the Indian Ocean basin mean is removed from our analysis (e.g., Fig S4).

617 The ROMS is configured for the tropical Indian Ocean $\left(30-110^{\circ} \mathrm{E}, 46^{\circ} \mathrm{S}\right.$ to $\left.32^{\circ} \mathrm{N}\right)$ with a 618 horizontal resolution of $1 / 3^{\circ} \times 1 / 3^{\circ}$ and 40 vertical sigma layers ${ }^{75}$, and forced by 3hourly 619 Japanese 55-year atmospheric reanalysis - drive ocean (JRA55-do ${ }^{76}$ ) fields (e.g, surface wind, 620 heat flux and precipitation) available from https://climate.mri-jma.go.jp/ htsujino/jra55do.html. 621 Along the eastern and southern boundaries, the mixed radiation-nudging boundary condition is 622 used, where temperature, salinity, and horizontal velocity are relaxed to the monthly values of 623 ORAS4 reanalysis data with the nudging time scale of 360 days (3 days) for the outflow (inflow)

624 case. With the open ocean boundary conditions, global sea level rise influence is included, and 625 there is no constraint for volume conservation over the Indian Ocean basin as is demonstrated by 626 the rapid basin-mean sea level rise (not shown).

627 To assess the role played by ENSO on interannual timescale and IPO on decadal timescale in 628 affecting Indian Ocean sea level, we perform a ten-member ensemble of the Pacific Ocean629 Global Atmosphere (POGA) pacemaker experiments using National Center for Atmospheric 630 Research (NCAR) Community Earth System Model version 1 (CESM125) from 1920-2019. In 631 this experiment ensemble, SST in the central and eastern tropical Pacific is restored to 632 observations but is fully coupled to the atmosphere elsewhere. The 10-member ensemble mean 633 fields of POGA experiments estimate the Pacific impacts on the Indian Ocean through both 634 atmospheric bridge and oceanic connection via the Indonesian Throughflow. Even though the 
635 model has some biases ${ }^{77}$, their results provide valuable assessments of remote forcing from the

636 Pacific especially in the context of analyzing these results with observations and standalone

637 OGCM simulations, as we have done here.

638 ROMS mixed layer heat budget analysis

639 Time evolution of the mixed layer temperature, $T_{\text {mix }}$, is governed by the following equation:

$$
\frac{\partial T_{\text {mix }}}{\partial t}=\underbrace{\frac{Q_{n e t}}{\rho C_{p} h}-\frac{Q_{s w}(z=-h)}{\rho C_{p} h}}_{\text {Surface heat flux }}
$$$$
\underbrace{-\frac{1}{h} \int_{-h}^{0}\left(u \frac{\partial T}{\partial x}\right) d z-\frac{1}{h} \int_{-h}^{0}\left(v \frac{\partial T}{\partial y}\right) d z+\frac{1}{h} \int_{-h}^{0} \nabla_{h} \cdot\left(\kappa_{h} \nabla_{h} T\right) d z}_{\text {horizontal advection \& mixing }}
$$

642

$$
\underbrace{-\frac{1}{h} \int_{-h}^{0}\left(w \frac{\partial T}{\partial z}\right) d z-\frac{1}{h}\left(\kappa_{v} \frac{\partial T}{\partial z}\right)_{z=-h}-\frac{\Delta T}{h} \frac{\partial h}{\partial t}}_{\text {Subsurface process }}
$$

643 where $T$ is the sea water temperature, $\rho$ represents the sea water density, $C_{p}$ is the specific heat of

644 the sea water, $(u, v, w)$ denote zonal, meridional and vertical velocity, respectively, and $h$ is the

645 mixed layer depth. The mixed layer depth $h$ is defined as a depth at which the potential density 646 increases by $0.01 \mathrm{~kg} / \mathrm{m}^{3}$ from the sea surface. $Q_{\text {net }}$ is the net surface heat flux and $Q_{s w}(z=$ $647-h)$ is the shortwave radiation at the bottom of the mixed layer. Additionally, $\kappa_{H}$ and $\kappa_{v}$ are 648 horizontal and vertical mixing coefficients, and $\Delta T$ is the temperature difference between the 649 mixed layer and upper thermocline. The first two terms on the right-hand side represent the 650 surface heat flux forcing; the third-to-fifth terms are zonal advection, meridional advection and 651 horizontal mixing. The last three terms represent subsurface processes: vertical advection, 
652 vertical mixing, and entrainment, respectively. The mixed layer heat budget is closed in the 653 ROMS experiment ${ }^{75,78}$.

\section{The Bayesian dynamical linear model}

655 To quantify forcing by remote equatorial wind and local longshore wind on sea level variability 656 along the Indonesian coast, we apply the Bayesian dynamic linear model (DLM) with two 657 predictors. The Bayesian DLM consists of two equations: an "observation equation" analogous 658 to the conventional multiple linear regression model (equation (1) below), and a "state equation" 659

660

661 that controls the dynamical evolution of coefficients $b_{i}(i=0,1,2)$ represented by equation (2).

$$
\begin{array}{lr}
Y(t)=b_{0}(t)+b_{1}(t) X_{1}(t)+b_{2}(t) X_{2}(t)+\varepsilon(t), & \varepsilon(t) \sim N(0, V(t)), \\
b_{i}(t)=b_{i}(t-1)+w_{i}(t), & w_{\mathrm{i}}(t) \sim N\left(0, W_{i}(t)\right) .
\end{array}
$$

In equation (1), $X_{1}$ and $X_{2}$ are the predictors, and $Y(t)$ is the predictand. The state equation

663

664

665

666

667

668

669

670

671

672

673

(2) means that the predictive distribution of $b_{i}$ at each time step $t$ (i.e., posterior) is updated based on its previous step $t$ - 1 distribution (i.e., prior) and the probability of observations $Y$ conditional on $b_{i}$ at time $t$ (i.e., the likelihood) using Bayes theorem ${ }^{26}$. Coefficients $b_{i}$ are obtained by applying Kalman filtering and smoothing, with the regression coefficient of conventional linear regression as its initial guess ${ }^{79,80}$. The $b_{0}(t)$ term represents a time-varying "intercept" whose variability is unexplained by the predictors $X_{i}$, while the $b_{i}$ terms represent the non-stationary influence of $X_{i}$ on $Y$, which is superior to the conventional regression model with stationary $b_{i}$ which can only estimate stationary impacts of the predictors ${ }^{79}$. Terms $\varepsilon(t)$ and $w_{i}(t)$ are independent white noises or errors, distributed normally with a mean of 0 and variances of $V(t)$ and $W_{i}(t)$. Here, we use zonal wind stress anomalies averaged over the equatorial area $\left(65^{\circ} \mathrm{E}-\right.$ $95^{\circ} \mathrm{E}, 5^{\circ} \mathrm{S}-5^{\circ} \mathrm{N}$ ) and longshore wind stress averaged along Sunatra and Java coast (supporting 
674 Figure S2) as the two predictors $\left(X_{1}\right.$ and $\left.X_{2}\right)$ and sea level anomalies along Indonesian coast as 675 the predictand, $Y(t)$. Time series of the equatorial wind $\left(X_{l}\right)$ leads Java coast sea level anomaly 676 by one month to consider the propagation time of equatorial Kelvin wave, but the local longshore 677 wind has no lag.

\section{Code and data availability}

679 Results from the OGCM experiments using ROMS and HYCOM, CESM1 Pacific Pacemaker 680 experiments and the Bayesian dynamic linear model, together with the IDL and Matlab codes for 681 carrying out the analyses, are available upon request.

682

683

684

685

686

687

688

689

690

691

692

693

\section{Methods references}

62 Pfeffer, J. \& Allemand, P. The key role of vertical land motions in coastal sea level variations: A global synthesis of multisatellite altimetry, tide gauge data and GPS measurements. Earth and Planetary Science Letters 439, 39-47 (2016).

63 Atlas, R. et al. A cross-calibrated, multiplatform ocean surface wind velocity product for meteorological and oceanographic applications. Bulletin of the American Meteorological Society 92, 157-174 (2011).

64 Wentz, F. et al. Remote Sensing Systems Cross-Calibrated Multi-Platform (CCMP) 6hourly ocean vector wind analysis product on 0.25 deg grid, Version 2.0. Remote Sensing Systems, Santa Rosa, CA (2015).

65 Reynolds, R. W. et al. Daily high-resolution-blended analyses for sea surface temperature. J. Climate 20, 5473-5496 (2007). 
69466 Beckley, B. et al. Global mean sea level trend from integrated multi-mission ocean 695 altimeters TOPEX/Poseidon Jason-1 and OSTM/Jason-2 Version 4.2. NASA Phys $696 \quad$ Oceanogr DAAC (2016).

69767 Cazenave, A. Global sea-level budget 1993-present. (2018).

69868 Rayner, N. et al. Improved analyses of changes and uncertainties in sea surface 699

700 temperature measured in situ since the mid-nineteenth century: the HadSST2 dataset.

70169 Henley, B. J. et al. A tripole index for the interdecadal Pacific oscillation. Climate

702 Dynamics 45, 3077-3090 (2015).

$70370 \quad$ Trenberth, K. et al. Observations: surface and atmospheric climate change. Chapter 3. 704 Climate change, 235-336 (2007).

70571 Kalnay, E. et al. The NCEP/NCAR 40-year reanalysis project. Bull. Amer. Meteor. Soc. 706 77, 437-471 (1996).

70772 Tozuka, T., Luo, J.-J., Masson, S. \& Yamagata, T. Decadal modulations of the Indian 708 Ocean dipole in the SINTEX-F1 coupled GCM. Journal of climate 20, 2881-2894 (2007).

70973 Song, Q., Vecchi, G. A. \& Rosati, A. J. Indian Ocean variability in the GFDL coupled $710 \quad$ climate model. Journal of climate 20, 2895-2916 (2007).

71174 Li, Y., Han, W., Wang, F., Zhang, L. \& Duan, J. Vertical Structure of the Upper-Indian 712 Ocean Thermal Variability. Journal of Climate 33, 7233-7253 (2020).

71375 Kido, S., Tozuka, T. \& Han, W. Anatomy of salinity anomalies associated with the 714 positive Indian Ocean Dipole. Journal of Geophysical Research: Oceans 124, 8116-8139 (2019). 
71676 Tsujino, H. et al. JRA-55 based surface dataset for driving ocean-sea-ice models

717 (JRA55-do). Ocean Modelling 130, 79-139 (2018).

71877 Deser, C. et al. ENSO and Pacific decadal variability in the Community Climate System

719 Model version 4. Journal of Climate 25, 2622-2651 (2012).

72078 Murata, K., Kido, S. \& Tozuka, T. Role of Reemergence in the Central North Pacific

721 Revealed by a Mixed Layer Heat Budget Analysis. Geophysical Research Letters 47, 722 e2020GL088194 (2020).

72379 Han, W. Q. et al. Decadal Variability of the Indian and Pacific Walker Cells since the 724 725 726 727 728 729 Acknowledgement

730 WH and LZ are supported by NASA Ocean Surface Topography Science Team award 731 NNX17AI63G and National Science Foundation award NSF-AGS 1935279. YL is supported by 732 the Strategic Priority Research Program of Chinese Academy of Sciences through grant 733 XDB42000000. GAM, AH, NR and GS are supported by the Regional and Global Model 734 Analysis (RGMA) component of the Earth and Environmental System Modeling Program of the 735 U.S. Department of Energy's Office of Biological \& Environmental Research (BER) via 736 National Science Foundation IA 1947282. This work also was supported by the National Center 737 for Atmospheric Research, which is a major facility sponsored by the National Science 
738 Foundation (NSF) under Cooperative Agreement No. 1852977. The ROMS simulation is

739 supported by the Cooperative Research Activities of Collaborative Use of Computing Facility of

740 the Atmosphere and Ocean Research Institute, the University of Tokyo. MJM is supported by

741 NOAA. PMEL contribution no. XXXX.

\section{Authors contributions}

743 W.H. led the project and did the main analyses and writing, L.Z. analysed CMIP6 model results

744 and carried out the experiments of the Bayesian Dynamic Linear Model and CESM1 extension

745 from 2013 to 2019, G.A.M., A.H., N.R. and G.S. carried out the CESM1 experiments from

746 1920-2013, helped setup the CESM1 extension experiments and did the post-processing, SK and

747 TT performed the ROMS experiments and provided the mixed layer heat budget analysis results,

748 M.J.M. contributed to the scientific results through stimulating discussions and analysis, A.C.

749 contributed to the analysis and discussion of satellite altimeter data, and B.J.W. helped to

750 confirm the effects of atmospheric intraseasonal oscillations. All authors contributed to writing

751 the paper. 


\section{Figures}

a Satellite sea level \& wind trend

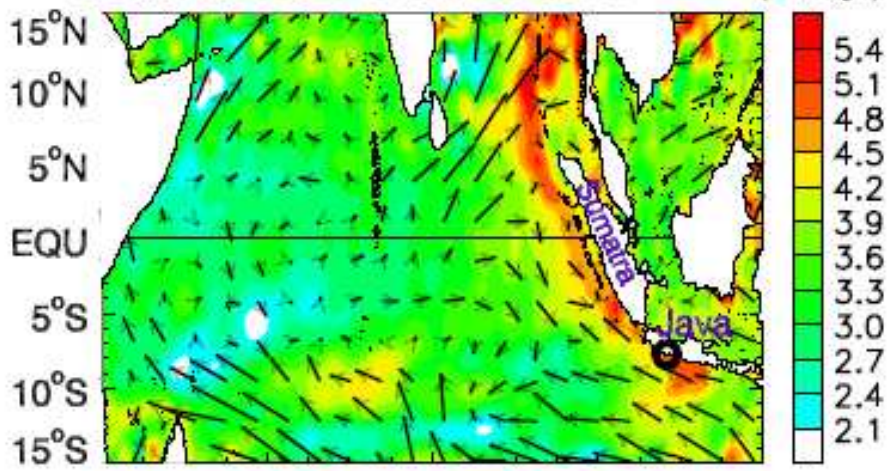

$(\mathrm{mm} / \mathrm{yr}) \quad$ b Satellite Surface Temperature trend $\left({ }^{\circ} \mathrm{C} / 100 \mathrm{yr}\right)$

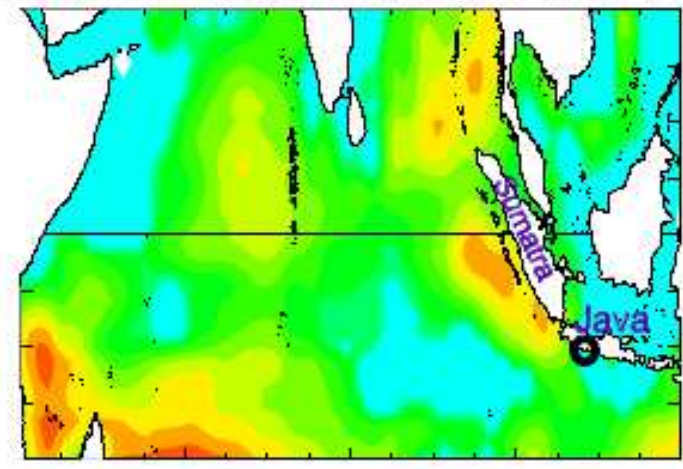

2.75

2.50

2.25

2.00

1.75

.50

1.25

1.00

0.50

0.00

$\begin{array}{lllll}40^{\circ} \mathrm{E} & 60^{\circ} \mathrm{E} & 80^{\circ} \mathrm{E} & 100^{\circ} \mathrm{E} & 120^{\circ} \mathrm{E}\end{array}$

$40^{\circ} \mathrm{E} \quad 60^{\circ} \mathrm{E} \quad 80^{\circ} \mathrm{E} \quad 100^{\circ} \mathrm{E} \quad 120^{\circ} \mathrm{E}$

c Sea level anomaly (SLA) \& sea surface temperature anomaly (SSTA) at tide gauge station

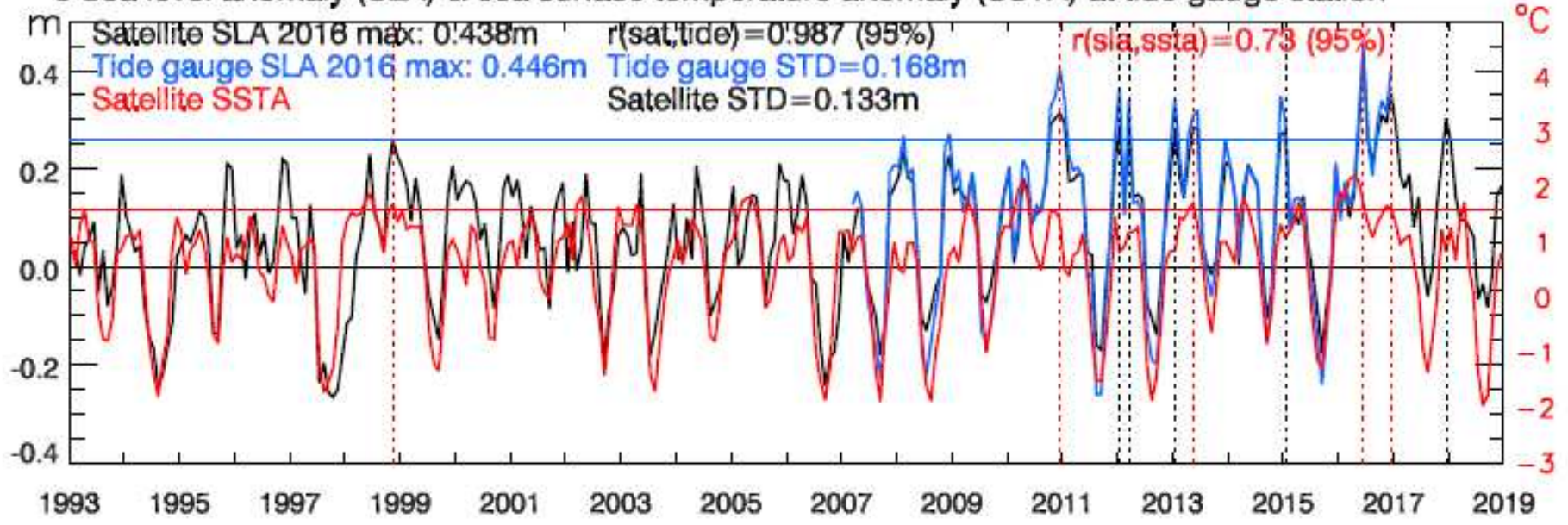

d Satellite observed \& model simulated SLA

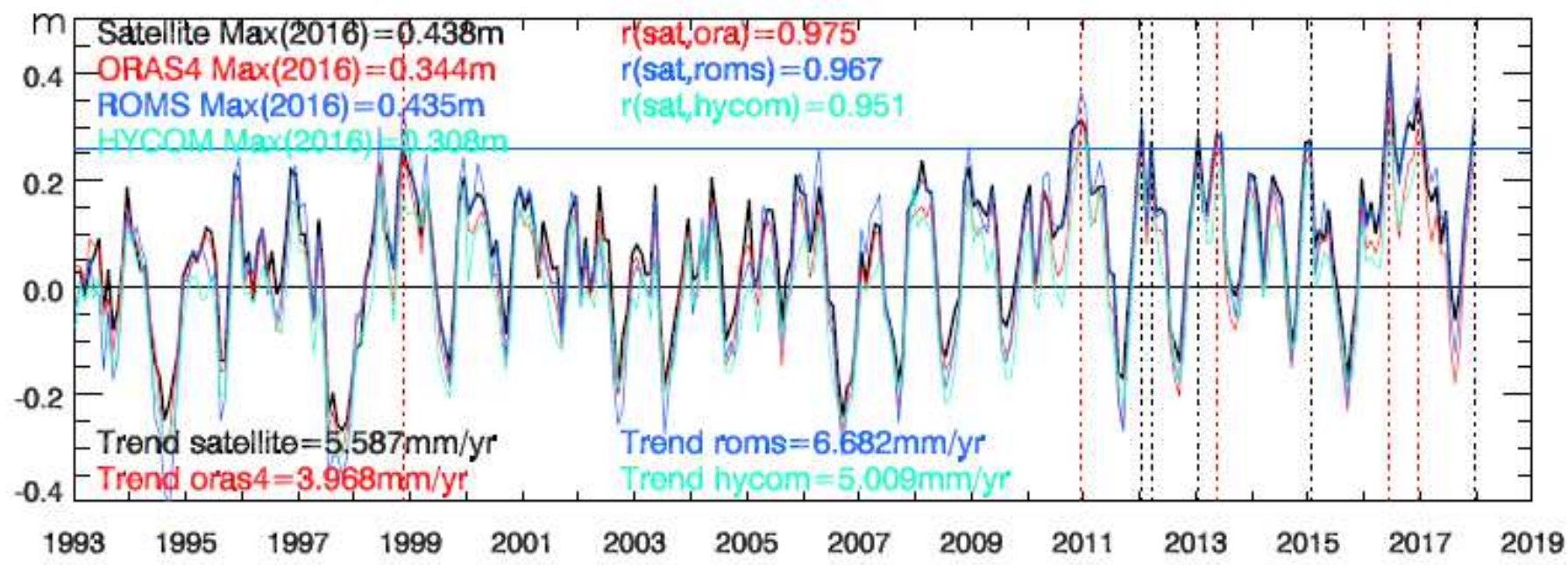

Figure 1

Trend map and timeseries of satellite-observed sea level, surface wind, and sea surface temperature (SST) and a tide gauge record at Java coast, marked by "o" in a and b. a, Linear trend of satellite sea level and cross-calibrated multiplatform (CCMP) surface wind stress from 1993-2018. b, Linear trend of satellite SST for 1993-2018. c, Time series of monthly mean sea level anomaly (SLA) from tide gauge 
station Cilacap B during 2007-2016 (blue curve); data from Permanent Service for Mean Sea Level, 2020 after correction for Glacial Isostatic Adjustment and inverted barometer effect) and from the multiplesatellite-merged altimeter data at the nearest grid point (black). The SLAs are relative to a 60yr mean (1958-2017) of ECMWF Ocean Reanalysis System 4 (ORAS4) data at the nearest location. Values exceeding 2 standard deviations (STD) of altimeter data (horizontal blue line) are identified as extreme events (indicated by vertical-dotted lines). Red dotted lines indicate sea level extremes cooccurred with marine heatwaves, dubbed Compound Height and Heat EXtremes (C-HHEX) events. d, Monthly SLAs from satellite (black, same as that of c), ORAS4 reanalysis data (red), simulations from two independent ocean general circulation models: ROMS and HYCOM (blue and green). See methods for data and models. Note: The designations employed and the presentation of the material on this map do not imply the expression of any opinion whatsoever on the part of Research Square concerning the legal status of any country, territory, city or area or of its authorities, or concerning the delimitation of its frontiers or boundaries. This map has been provided by the authors.
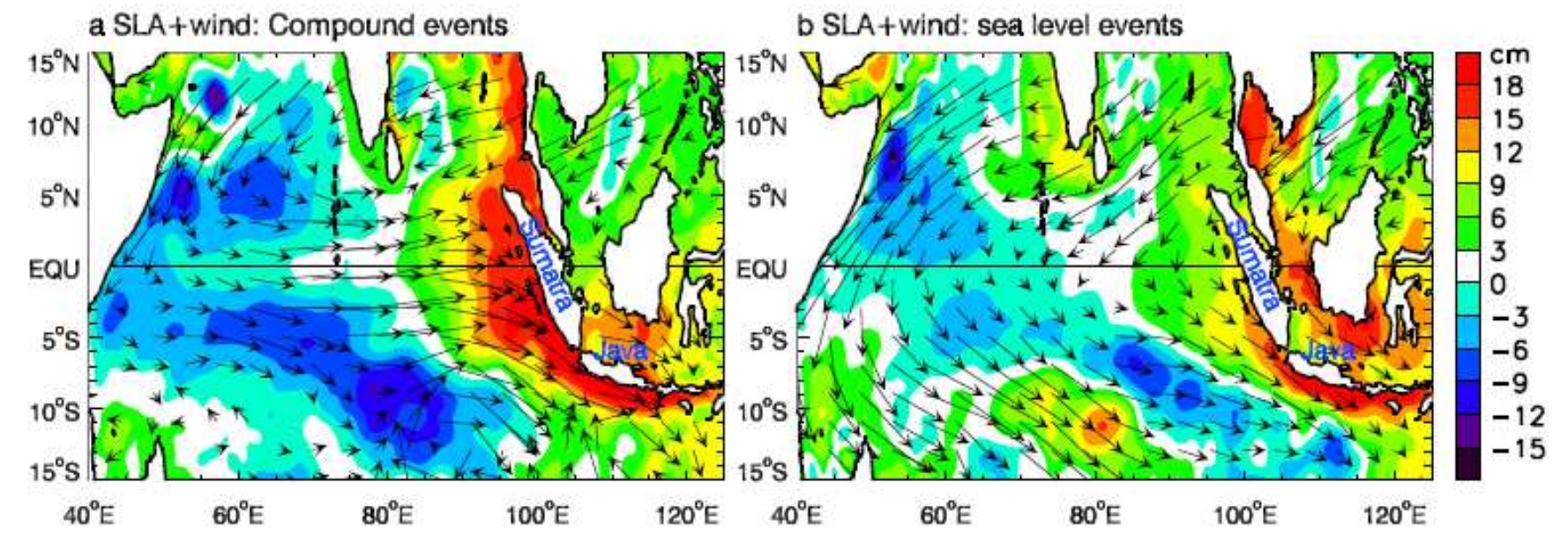

c SSTA+wind: compound events
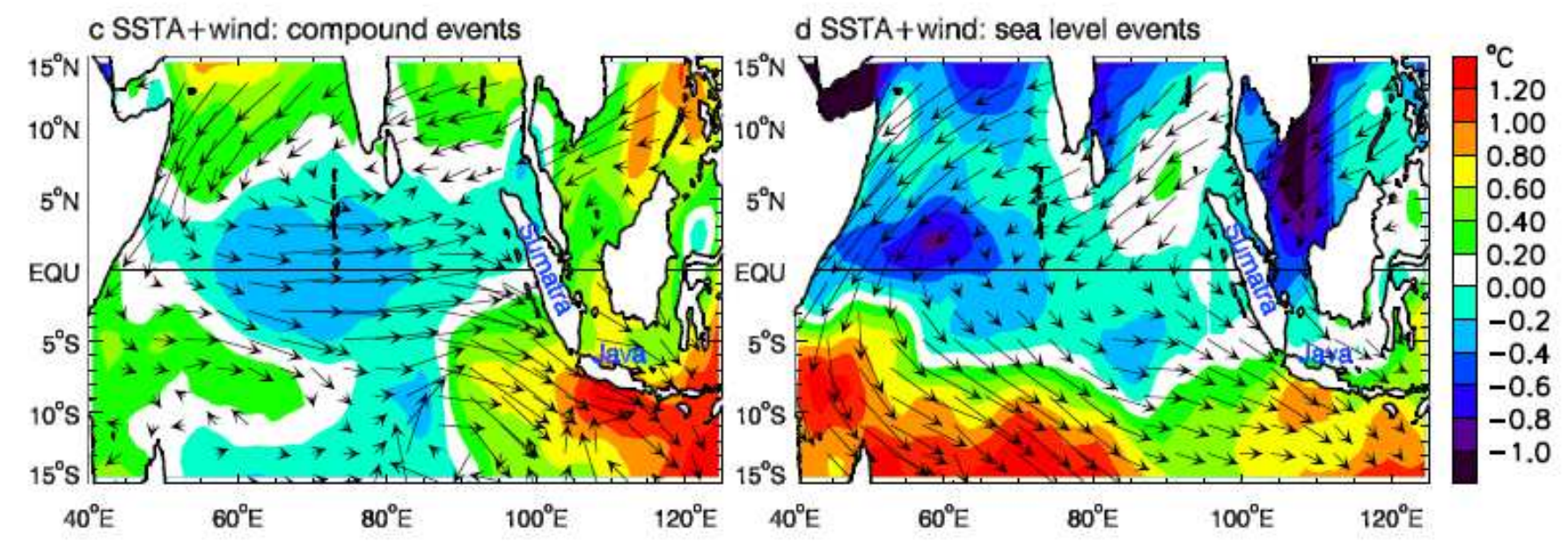

\section{Figure 2}

Composite of satellite-observed monthly sea level anomaly (SLA), surface wind stress anomaly, and sea surface temperature anomaly (SSTA) for the peak months of five compound height and heat extremes (CHHEX) and five sea level alone extreme events. All anomalies are relative to 1993-2018 mean. a \& b, Composites of SLA (color) and surface wind stress (arrows) for C-HHEX and sea level events; c \& d, The 
same as $a \& b$ but for their corresponding SSTA and surface wind stress. Wind vectors are the average for the event peak month and the preceding month, considering the propagation time of equatorial Kelvin waves that impact SLA and SSTA. Note: The designations employed and the presentation of the material on this map do not imply the expression of any opinion whatsoever on the part of Research Square concerning the legal status of any country, territory, city or area or of its authorities, or concerning the delimitation of its frontiers or boundaries. This map has been provided by the authors.

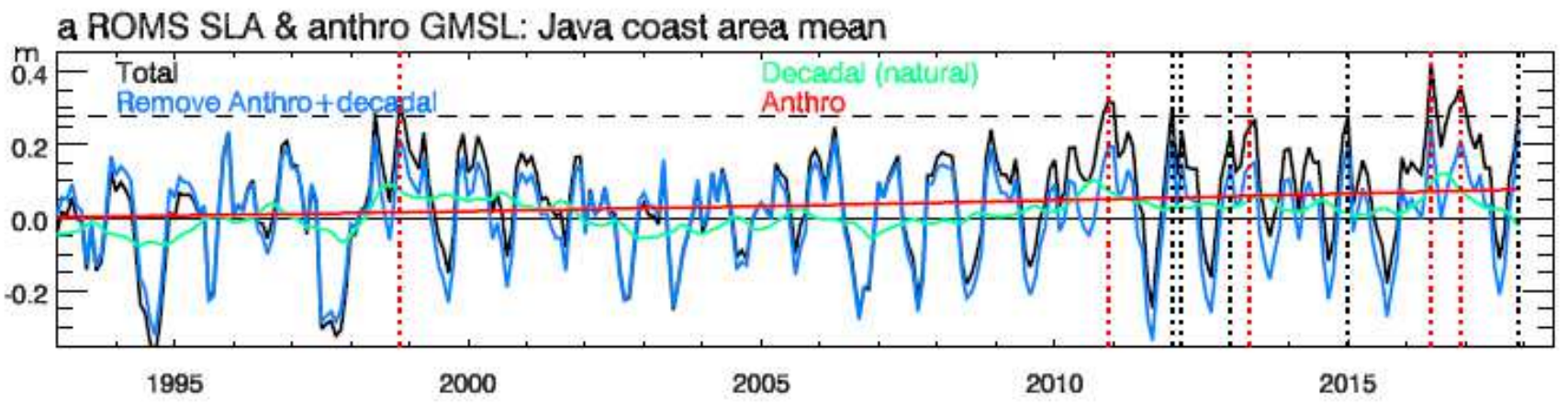

b Decadal SLA: ROMS \& CESM1 Pacific forcing

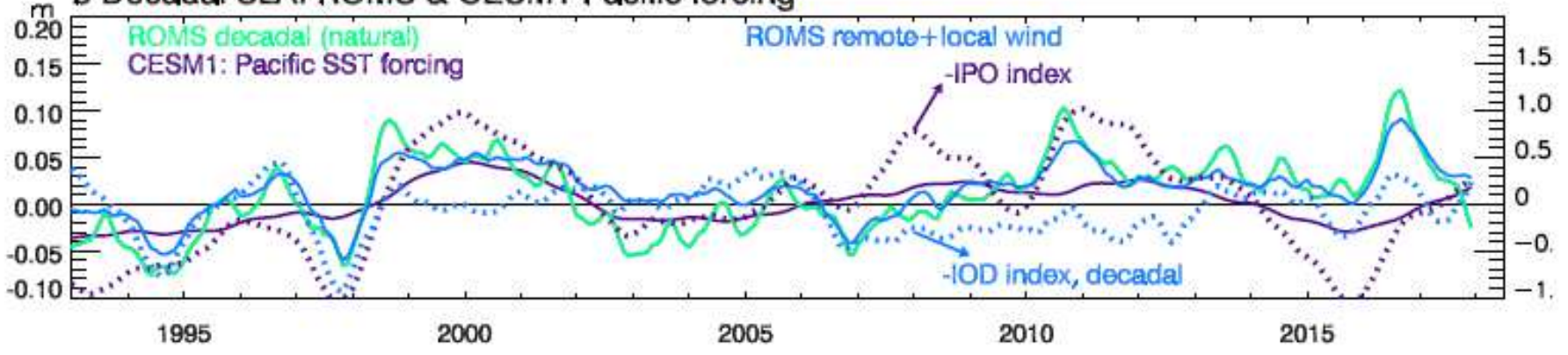

c ROMS season + interannual SLA: Remote \& Local wind forcing

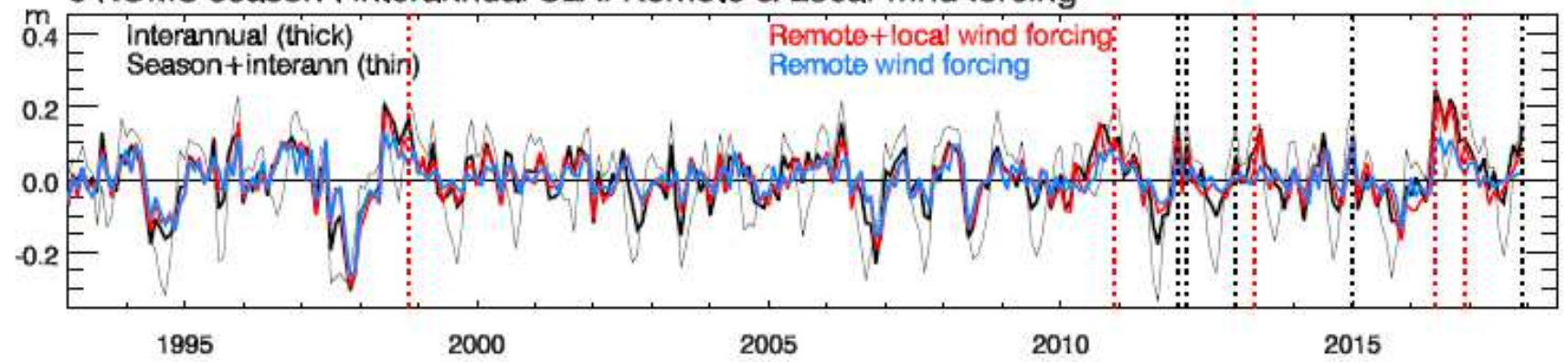

d Normalized climate indices

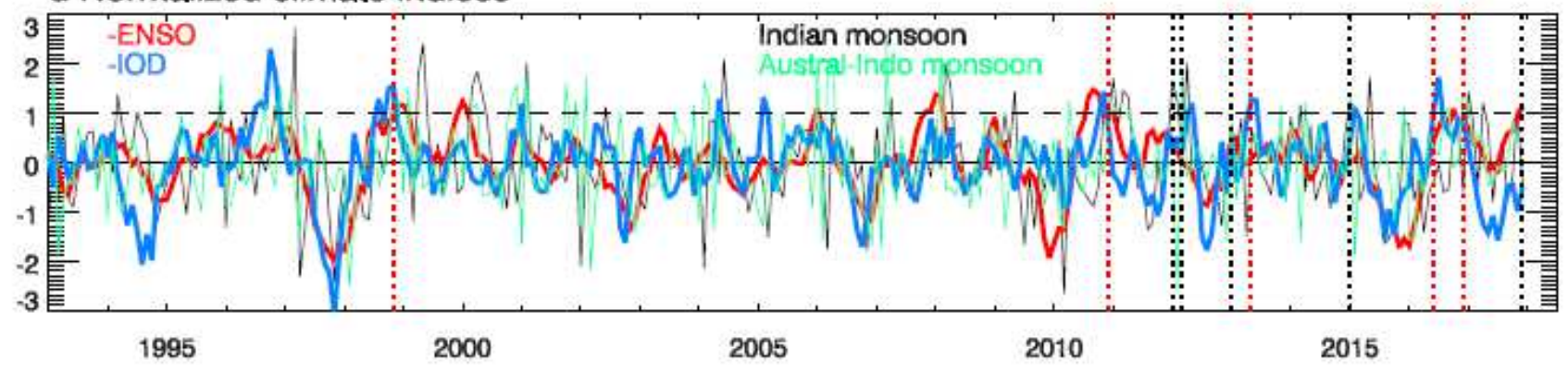

Figure 3 
Time series of monthly sea level anomalies (SLAs) averaged over Java coastal area (Supplementary Fig S2), anthropogenically-induced global mean sea level rise (GMSLR) and climate indices. Calculations are done for 1960-2017 period but only 1993-429 2017 is shown for clarity. The 1960- 2017 mean is removed from each series. a, ROMS simulated total SLA (black), anthropogenic GMSLR (red), ROMS natural decadal SLA (8yr lowpass filtered with anthropogenic GMSLR removed; green), and ROMS seasonal-tointerannual SLA (blue). b, ROMS decadal SLA (green), SLA caused by remote equatorial wind and local longshore wind assessed from Bayesian Dynamic Linear Model (DLM; blue), SLA from the 10-member ensemble mean of Pacific Pacemaker experiment using Community Earth System Model version 1 (CESM1) - assessing the impacts of tropical Pacific sea surface temperature anomaly (purple) - and index of the Interdecadal Pacific Oscillation (IPO; dotted purple). Labels on the right indicate normalized indices of IPO and decadal variability of Indian Ocean Dipole (IOD). Decadal variability of Indian and Australian-Indonesian monsoon winds follow IPO index and thus not shown. c, ROMS seasonal-tointerannual SLA (think black), interannual SLA with seasonal variability removed (thick black), interannual SLA forced by remote equatorial and local longshore winds (red), and SLA forced only by remote equatorial wind (blue). d, Normalized indices of the El Niño-Southern Oscillation (ENSO; red), IOD (blue), Indian monsoon wind index (black; one month lead) and Australian-Indonesian monsoon index (green). See Methods for more details.

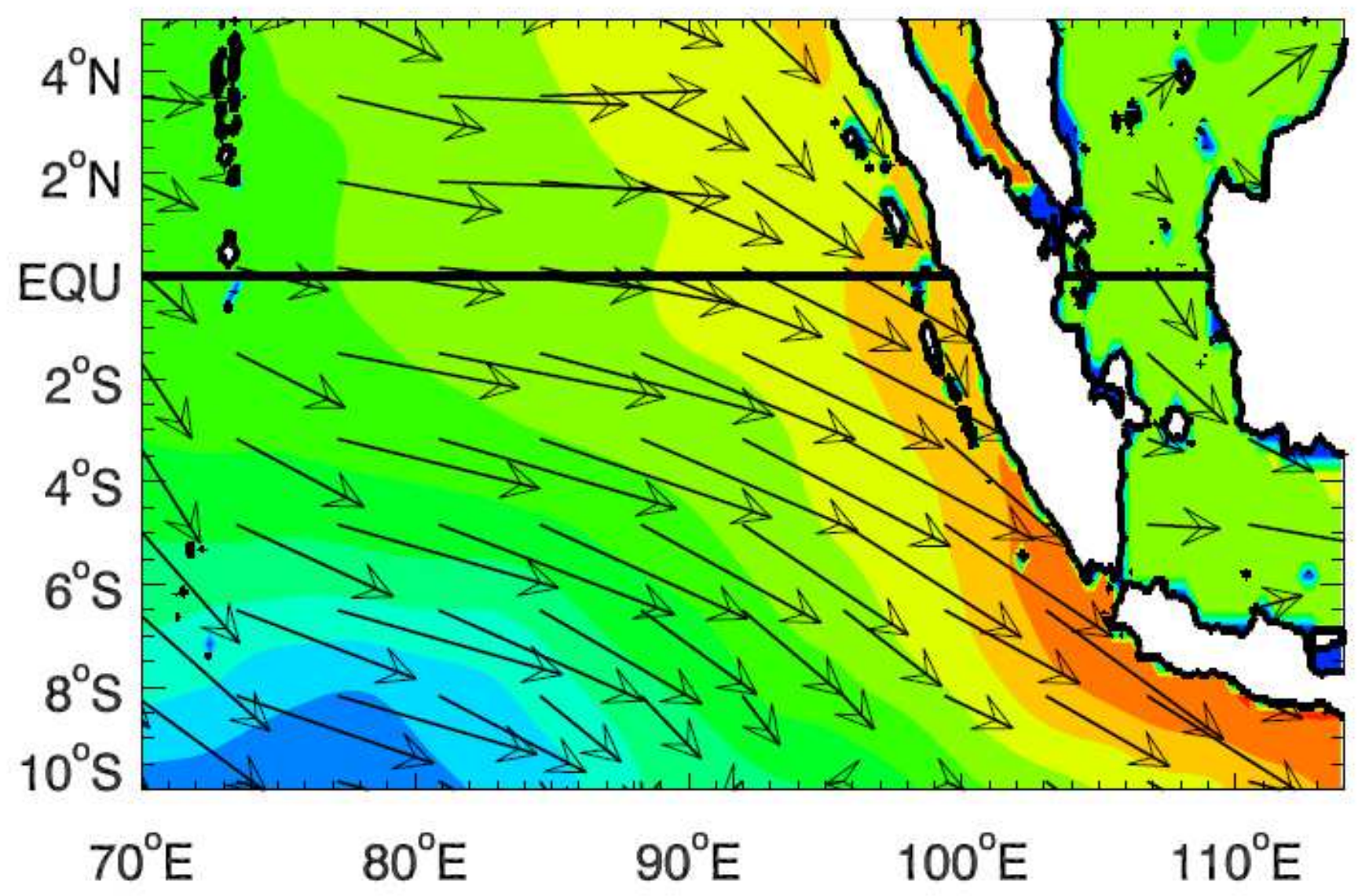

Figure 4 
Internal decadal (8yr lowpass filtered) anomalies of surface wind stress (arrows) and sea level (color) averaged for 2010-2017, based on the monthly JRA55-do reanalysis winds that force the ROMS (see methods) and ROMS simulated SLAs relative to the 1960-2017 mean. Linear trend of winds and anthropogenic global mean sea level are removed before we apply then 8yr lowpass filter.Note: The designations employed and the presentation of the material on this map do not imply the expression of any opinion whatsoever on the part of Research Square concerning the legal status of any country, territory, city or area or of its authorities, or concerning the delimitation of its frontiers or boundaries. This map has been provided by the authors.
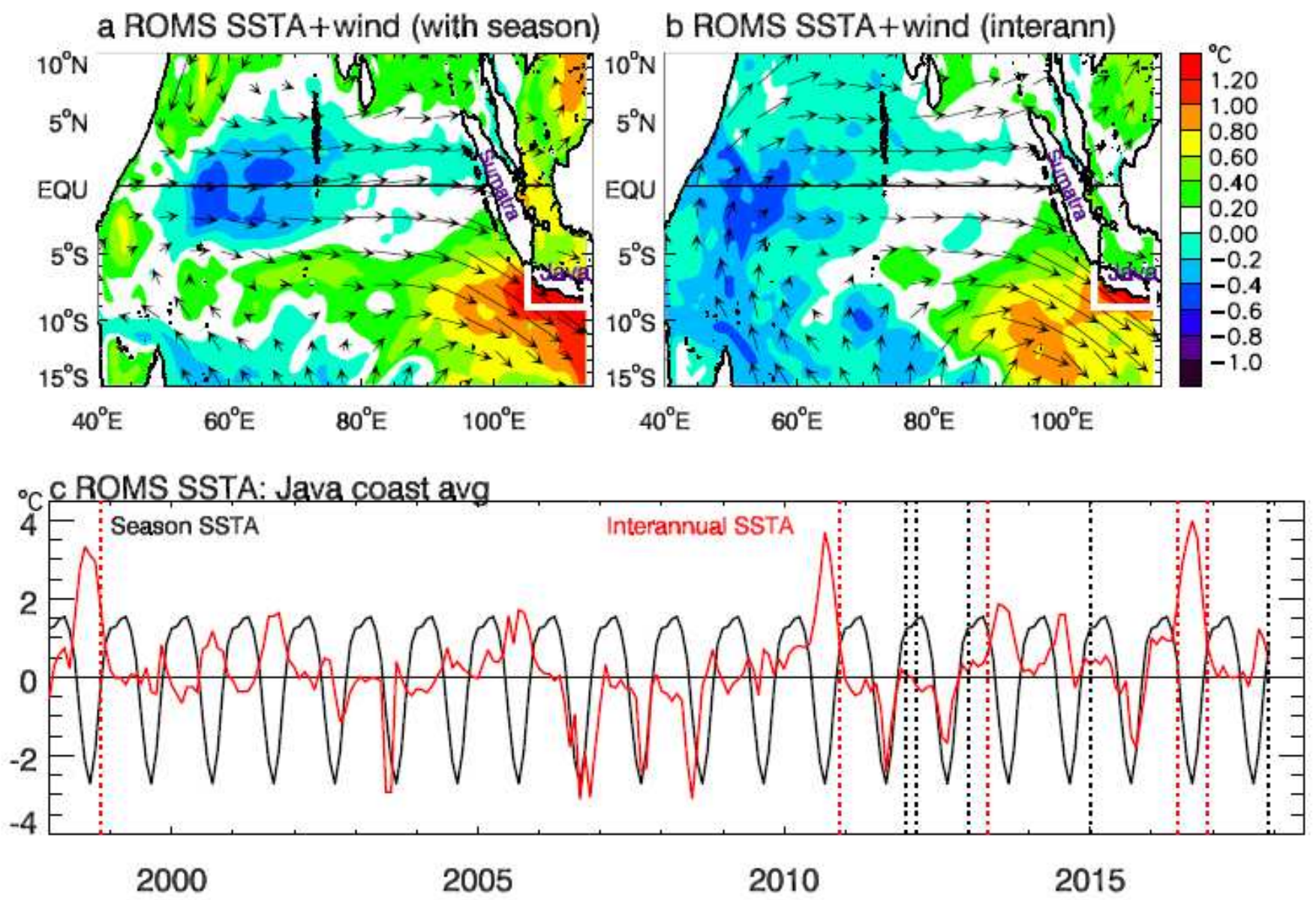

${ }^{\circ} \mathrm{C} / \mathrm{mo}$ d ROMS SSTA budget

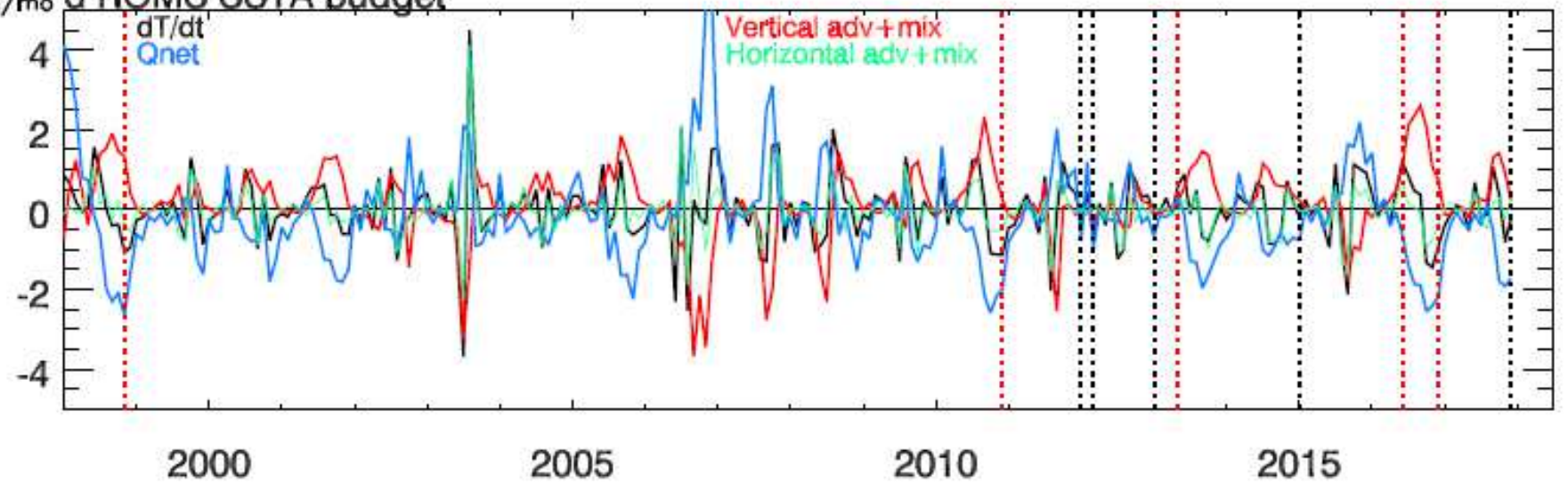

Figure 5 
Composites of ROMS simulated sea surface temperature anomaly (SSTA) and surface wind anomalies (from JRA55-do reanalysis data that force ROMS) for the five C-HHEXs and time series of SSTA averaged in Java coastal area (Fig S2). a, Composite SSTA (color) and surface wind (arrows) anomalies with the 1993-2017 mean removed but seasonal variability retained to be consistent with Fig 2 from observations. b, The 453 same as a but with seasonal variability removed. c, Timeseries of mean seasonal variability (black) and variability with seasonal anomaly removed which primarily represents interannual variability (red). $d$, Terms of heat budget analysis for SSTA (red curve in b): time changing rate of SSTA from all processes (dT/dt, black), from net surface heat flux (blue), from subsurface processes (upwelling+mixing, red) and horizontal advection+mixing (green). Units: degree per month. Note: The designations employed and the presentation of the material on this map do not imply the expression of any opinion whatsoever on the part of Research Square concerning the legal status of any country, territory, city or area or of its authorities, or concerning the delimitation of its frontiers or boundaries. This map has been provided by the authors.

\section{Supplementary Files}

This is a list of supplementary files associated with this preprint. Click to download.

- Paper21nccsupplementary.pdf 